\title{
Development of a Detailed Microphysics Cirrus Model Tracking Aerosol Particles' Histories for Interpretation of the Recent INCA Campaign
}

\author{
Marie Monier, Wolfram Wobrock, Jean-François Gayet, and Andrea Flossmann \\ Laboratoire de Météorologie Physique, OPGC/Université Blaise Pascal/CNRS, Clermont-Ferrand, France
}

(Manuscript received 27 June 2004, in final form 28 June 2005)

\begin{abstract}
Cirrus clouds play an important role in the earth's energy balance. To quantify their impact, information is needed on their microstructure and more precisely on the number and size of the ice crystals. With the anthropogenic activity, more and more aerosol particles and water vapor are released even at the altitude where cirrus clouds are formed. Cirrus clouds formed in a polluted air mass may have different microphysical properties and, therefore, a different impact on the climate system via the changed radiative properties compared to background cirrus clouds. To study this aspect, the European project called the Interhemispheric Differences in Cirrus Properties due to Anthropogenic Emissions (INCA) measured the microphysical properties of cirrus clouds together with the physical and chemicals properties of aerosol particles in clean air (at Punta Arenas, Chile) and polluted air (at Prestwick, Scotland). The goal of the present work was to develop a detailed microphysics model for cirrus clouds for the interpretation and the generalization of the INCA observations. This model considers moist aerosol particles through the Externally Mixed (EXMIX) model, so that the chemical composition of solution droplets can be followed. Ice crystal formation is described through homogeneous or heterogeneous nucleation. The crystals then grow by deposition. With this model, the interactions between the microphysical processes, simulated ice crystal concentrations, and dimensional distributions of the INCA observations were studied, and explanations were provided for the observed differences between background and polluted cirrus clouds.
\end{abstract}

\section{Introduction}

Cirrus clouds play a key role in the earth's energy budget through three different mechanisms. First, they reflect a part of the incoming solar radiation; the magnitude of this effect is controlled by their vertical structure and particularly their microphysical composition (shape, number, and size of the ice crystals). Second, they trap a part of the outgoing infrared radiation from the earth's surface and lower troposphere. Third, they also participate in atmospheric chemistry (Brune et al. 1999; Reichardt et al. 1996), which can change the atmospheric chemical content and thus the oxidizing capacity of the atmosphere. In the upper troposphere, poor in particles, ice crystals offer a surface for the gas to be involved in chemical reactions through heterogeneous mechanisms. The total ice surface (i.e., the ice

Corresponding author address: Prof. Andrea I. Flossmann, LaMP, Université Blaise Pascal, 24 avenue des Landais, 63177 Aubière, France.

E-mail: Andrea.Flossmann@opgc.univ-bpclermont.fr crystal shape and size distribution) controls the magnitude of this effect. The net effect of these processes can lead to negative but also positive radiative forcing ( $\mathrm{Ra}-$ manathan and Collins 1991). Cirrus clouds have therefore been the subjects of thorough investigation in the last decades. Numerous experiments [the First International Satellite Cloud Climatology Project (ISCCP) Regional Experiment (FIRE), the Subsonic Aircraft Contrail and Cloud Effects Special Study (SUCCESS), the European Cloud Radiation Experiment (EUCREX), the International Cirrus Experiment (ICE), Aerosol Condensation Trail (AEROCONTRAIL), and the Interaction of Aerosol and Cold Clouds (INTACC); Heymsfield et McFarquhar 2002] have raised our knowledge by providing in situ data on cirrus cloud systems. Several theoretical models of cirrus cloud have been developed from that knowledge. A wide panel of available models at different scales is given in Sundqvist (2002), Jakob (2002), Starr and Quante (2002), and Khvorostyanov and Sassen (2002). Additionally, a review of available models at the microphysical scale is given in Lin et al. (2002). 
Altitudes where cirrus clouds are commonly encountered are the upper troposphere. Air traffic injects water vapor and aerosol particles and changes the composition of the upper troposphere. One impact is the formation of contrails resulting in an increase in contrail coverage (Gierens et al. 1999). In a second place, jet engine exhaust could trigger cirrus cloud formation. Ice nuclei are produced by the gas-to-particle conversion and are also released by contrail evaporation. Aircraft emissions may then have caused observable longterm increases in cirrus occurrence frequency and amounts (Boucher 1999) with a possible large impact on radiative forcing (Houghton et al. 2001). Research is ongoing to understand, additionally, if cirrus clouds formed on anthropogenic ice nuclei will have microphysical properties differing from natural cirrus clouds.

For this purpose, the flight campaign known as the Interhemispheric Differences in Cirrus Properties due to Anthropogenic Emissions (INCA; Ström 2001) took place in 2000 to provide comparable datasets of "polluted" versus "natural" cirrus clouds. The Falcon airplane from the Deutsches Zentrum für Luft- und Raumfahrt (DLR), Germany, was equipped with a number of instruments to characterize the microphysical properties of cirrus clouds, the physical and chemical properties of the particles free in the air and contained in the ice phase, as well as the amounts of a few trace gases. Two flight campaigns were performed, one at Punta Arena, Chile (hereafter PA), and one at Prestwick, Scotland (hereafter PR), in the same season: autumn (March-April for PA, September-October for PR) within the same year (2000). These two sites were chosen for two different reasons. The first is the similarity of their latitudes (about $50^{\circ}$ ). The second is the contrast in anthropogenic sources near the two sites. The PA site represents a clean atmosphere, while PR is an area highly exposed to anthropogenic emissions. The particle-polluted aspect of the PR region is obvious through the entire troposphere from the measurements of aerosol concentration (Minikin et al. 2003). The use of the combination of an optical particle counter and a Fast Forward Scattering Probe (FSSP) to count and size the ice crystals makes the presence of a very strong concentration of small crystals (length under $20 \mu \mathrm{m}$ ) obvious. Their concentration ranges from a few to 20 ice crystals per cubic centimeter (Gayet et al. 2002). They represent $20 \%$ of the total ice water content of the clouds and $50 \%$ of the total extinction measured by the Polar Nephelometer and derived from the Particle Measuring System (PMS) probe measurements as well (Gayet et al. 2004). Previous campaign observations, in which the use of the FSSP was not common, showed total concentration of ice crystals smaller by a factor between 10 and 100 (Dowling and Radke 1990; Heymsfield and McFarquhar 2002). The INCA measurements also showed that for the PR campaign the concentration of ice crystals is twice the mean concentration of the PA campaign (about 1 ice crystal $\mathrm{cm}^{-3}$ for PA and 2 for PR). This difference in concentration is associated, for cirrus clouds sampled in supersaturated regions, with larger effective diameter of ice crystals for PA, with differences up to $10 \mu \mathrm{m}$ (Gayet et al. 2004). A thorough view of results depicted by the INCA experiment is available in the European final report (Ström 2001, which can be found online at http://www.pa.op. dlr.de/inca/).

Thus, the measurements of the INCA campaign seem to show differences in the microphysical properties of the cirrus clouds sampled over both a clean area and a highly polluted one. To understand these differences and to generalize these analyses, modeling studies are necessary. Some of the conclusions of the INCA campaign arose from the comparison of the measurements of residual and interstitial aerosol properties. To understand the INCA observations and conclusions, we need a model capable of fully describing aerosol and cirrus clouds interactions, that is, to follow the aerosol content and its chemical properties inside the ice crystals. We thus developed a cirrus cloud model with detailed microphysics that explicitly describes aerosol content and chemical composition for interstitial wet aerosol particles and also ice crystals. To entirely describe the aerosol content of the ice crystal particle, we also took into account, in our model, the impact of the interstitial wet aerosol particles by the ice crystals. The objective of the present work is to understand how the chemistry and the concentration of wet aerosols influence the formation of cirrus clouds. Our model successfully simulates the very high ice crystals concentration and the crystals size distributions observed in natural cirrus clouds during the INCA campaign and also simulates residual aerosol size distribution in agreement with the INCA observations.

The paper is organized in six sections. Section 2 provides a description of the dynamics and microphysics of the new cirrus cloud model; section 3 presents the results of sensitivity tests of the parameters that influence the ice crystal concentrations. Studies regarding consequences on the residual aerosols are presented in section 4 . In section 5 we investigate the capability of the model to reproduce particle size distributions in agreement with the INCA observations. Finally a proper case study is done in section 6. Further discussion and conclusions are provided in section 7 . 


\section{Description of the model}

To put the emphasis on a detailed treatment of the explicit microphysics we have used a simplified dynamics model. Two different dynamical frameworks are used: a simple air parcel model and a one-dimensional vertically resolved model. For the microphysics of cirrus clouds, we assume that aerosol particles are an internal mixing of sulfuric acid and some inactive material as silicates. Therefore, their humidification by condensation leads to sulfuric acid solution droplets with an insoluble core. Under favorable thermodynamics conditions, these droplets can freeze and the ice phase can be initiated either in the liquid phase of the solution droplets (nucleation is then defined as homogeneous) or at the surface of the insoluble core (heterogeneous nucleation and more accurately, a condensationfreezing mechanism). The ice crystals subsequently formed can then grow by vapor diffusion or by collection of solution droplets through Brownian motion, phoretic effects, or inertial impaction.

\section{a. Modeling of dynamical processes}

\section{1) Air PARCEl MODEL}

This Lagrangian model is based on the elementary theory of an air parcel in free convection. Vertical motion of air parcels can be generated either by buoyancy or mechanical forces. The heat, mass, and moment transport then induced is responsible for cloud formation. The air parcel is assumed to be adiabatic and homogeneous. That means that it maintains its identity during thermodynamics processes as no heat or mass exchange with the environment is possible and that the properties of the air parcel are assumed to be uniform everywhere. The air parcel pressure adjusts instantaneously to that of the surrounding air, which is in hydrostatic equilibrium. The vertical velocity is prescribed. Our set of equations for the temperature, pressure, density, and humidity of the air is identical to that described in Pruppacher and Klett [1997; from their Eqs. (12-26)-(12-35)]. However, as the updraft is not large, we assume entrainment to be negligible.

This simple model has the advantage to completely control interactions between dynamics and microphysics. We will then use this framework to study each microphysical process and their interactions. However, the absence of sedimentation of large ice crystals represents a limitation to adequately model cirrus clouds. That is why we equally deployed a vertically resolved cirrus cloud model.

\section{2) Vertically RESOlVED CIRRUS CLOUd MODEL}

We used the cylindrical model, which was first presented by Asai and Kasahara (1967) for their study of cumulus cloud formation and evolution. Two concentric cylinders model the air as represented in Fig. 1: the inner cylinder represents the convective cell and the outer cylinder the surrounding subsidence. Lateral exchanges between the two cylinders are allowed through the $\tilde{u}$ velocity. This model is thus not strictly one-dimensional. In this model radial symmetry is assumed. The radius of the outer cylinder is set to be at least 10 times greater than the inner radius, so that the environment can be assumed to be insensitive to the fluctuations of the cloudy column. The pressure of the inner cylinder adjusts instantaneously to that of the outer. Microphysical processes are computed only in the inner cylinder. The model equations in the form of flux divergence are given by

$$
\begin{aligned}
0 & =-\frac{1}{\rho} \frac{\partial(\rho w)}{\partial z}-\frac{2}{r_{1}} \tilde{u}, \\
w_{e} & =\frac{\sigma^{2}}{\sigma^{2}-1} w, \\
\frac{\partial(\rho w)}{\partial t} & =-\frac{\partial(w \rho w)}{\partial z}-\frac{2}{r_{1}} \rho \tilde{w} \tilde{u}+\frac{2}{r_{1}} \alpha^{2} \rho\left|w_{e}-w\right|\left(w_{e}-w\right)+\left[\frac{\theta_{v}-\theta_{v e}}{\theta_{v e}}-\left(q_{c}+q_{i}\right)\right] \rho g, \\
\frac{\partial(\rho \theta)}{\partial t} & =-\frac{\partial(w \rho \theta)}{\partial z}-\frac{2}{r_{1}} \rho \tilde{\theta} \tilde{u}+\frac{2}{r_{1}} \alpha^{2} \rho\left|w_{e}-w\right|\left(\theta_{e}-\theta\right)+\left.\frac{L}{c_{p}} \frac{\partial \rho q_{v}}{\partial t}\right|_{\text {mic }}+Q_{\text {diab }}, \\
\frac{\partial\left(\rho q_{v}\right)}{\partial t} & =-\frac{\partial\left(w \rho q_{v}\right)}{\partial z}-\frac{2}{r_{1}} \rho \tilde{q} \tilde{u} \tilde{u}+\frac{2}{r_{1}} \alpha^{2} \rho\left|w_{e}-w\right|\left(q_{v e}-q_{v}\right)+\left.\frac{\partial \rho q_{v}}{\partial t}\right|_{\text {mic }}, \\
\frac{\partial f_{\text {wat } / \text { ice }}}{\partial t} & =-\frac{\partial\left[\left(w+U_{\infty, \text { drop/crys }}\right) f_{\text {wat } / \text { ice }}\right]}{\partial z}-\frac{2}{r_{1}} \tilde{f}_{\text {wat } / \text { ice }} \tilde{u}+\frac{2}{r_{1}} \alpha^{2}\left|w_{e}-w\right|\left(f_{\text {wat } / \text { ice }, e}-f_{\text {wat/ice }}\right)+\frac{\left.\partial f_{\text {wat } / \text { ice }}\right|_{\text {mic }} .}{\partial t}
\end{aligned}
$$




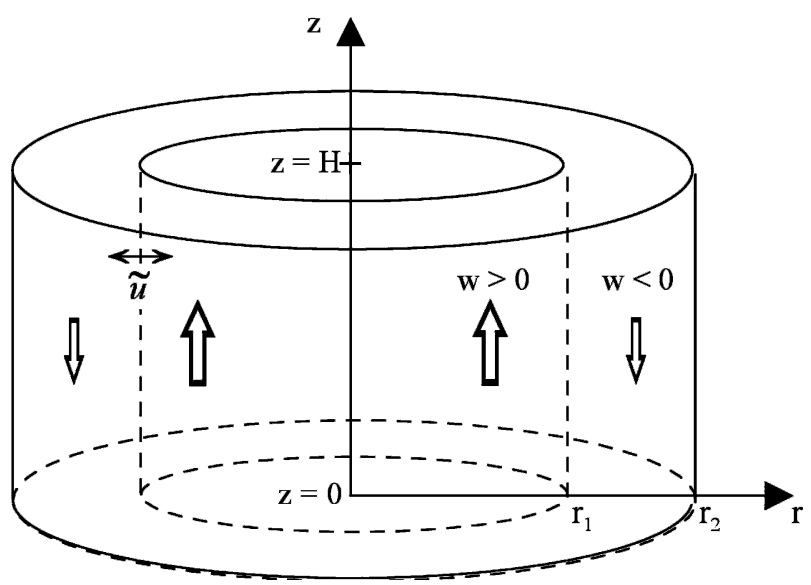

FIG. 1. Schematic view of the cloudy (radius $r_{1}$ ) and subsidence (radius $r_{2}$ ) columns both with a height $H$ for the $1-1 / 2$ dimensional model. The radial velocity $\tilde{u}$ drives exchange between the two cylinders.

For a symbol list see the appendix. The variables with an $e$ subscript represent the outer cylinder values, the one with a tilde are the boundary values, and all others are the inner cylinder values. The boundary values are defined following von der Emde and Kahlig (1989). Diabatic heating due to radiation in the potential temperature equation is not considered in our study. Time integration once ice crystals are formed is short. Since we only focused on cirrus cloud formation regions, this is not of large consequence for our study. The bottom layer is assumed to be a constant source of moisture temperature and particles. The top layer is hermetical but far enough from the updrafts to prevent significant convergence of heat, moisture, and particles.

During the INCA campaign, observations mainly focused on cirrus clouds not resulting from deep convection. The authors are aware that this special dynamical framework was designed to model cumulonimbus towers and that there are no theories or observations to support local environmental subsidence around cirrus "cells" as a general response of the atmosphere. However, this model was available at our institute, developed for other applications (cumulus simulation), and we have modified certain parameters of the cumulus model in such a way that it quite closely reproduces the conditions in and around cirrus clouds. This was done by increasing the radius of the outer cylinder in such a way that the environment is almost at rest. Thus, in our modeling studies on the short duration of the integration, the exchanges between the two cylinders were negligible in the evolution of the clouds and, in fact, the dynamics became those of a purely 1D situation.

For the calculations, we use a time-splitting proce- dure and compute the evolution of the variables due to dynamical processes first; once this is done we compute the microphysical changes using the new conditions and then update the thermodynamic parameters. The time step is set to $2 \mathrm{~s}$; however, for the processes using advection, a time-splitting procedure could be applied in order to guarantee the Courant-Friedrich-Levy criterion. The inner cylinder has a radius of $3.5 \mathrm{~km}$ and the outer, a radius of $35 \mathrm{~km}$. The advection scheme for the vertical flux divergence is the Multidimensional Positive Definite Advection Transport Algorithm (MPDATA) scheme developed by Smolarkiewicz (1983). The terminal velocities for liquid particles are taken from Pruppacher and Klett (1997) and for ice crystals from Heymsfield and Iaquinta (2000).

\section{b. Modeling of microphysical processes}

Our microphysical module is based on the warm microphysics model, Externally Mixed (EXMIX) presented in Wobrock et al. (2001). Aerosol particles grow by water vapor diffusion to solution droplets or to cloud droplets. At cold temperatures and under ice-supersaturated conditions, we have extended EXMIX to consider that aerosol particles can also be ice nuclei and form ice crystals.

The strength of the EXMIX model for warm clouds is that the particles' histories are not lost during the numerical integration as bin models typically do. This model allows us to study the cloud composition from two different approaches. Similar to almost all bin models, we can study the microphysical processes inside the cloud by the knowledge of number and sizes of cloud droplets and aerosol particles. Another interesting aspect to studying the microphysical processes inside the cloud is to follow the behavior of aerosol particles that can remain in the interstitial air or be immerged in the condensed phase of the cloud. EXMIX can describe this second approach as it tracks the aerosol particles without any assumptions such as a cut-size diameter for the aerosol particles' activation. This last way is quite useful when trying to understand the formation of the cloud. During the INCA campaign a counterflow virtual impactor (CVI) probe was used for measurements of the residual aerosol particles. We then decided to use the EXMIX philosophy to perform a case study on this campaign and extended it for cold clouds.

The capability of the model to track the particles histories comes from the formulation of the number distribution of droplets. The number size distribution of droplets, $f_{\text {wat }}\left(m, m_{\mathrm{AP}, N}, x_{i}\right)$, is indeed treated as a function of the total particle mass $m$, the dry aerosol mass $m_{\mathrm{AP}, N}$, and the chemical composition $x_{i}$ of the aerosol 
particle. In this study only one type of aerosol particle is treated and there is no external mixture, so the number distribution of liquid particles resumes in that case to $f_{\text {wat }}\left(m, m_{\mathrm{AP}, N}\right)$. If $m \gg m_{\mathrm{AP}, N}$ activated drops are present while for inactivated solution droplets $m$ and $m_{A P, N}$ typically differ only by a factor of 3 or less. For $m=m_{\mathrm{AP}, N}, f_{\mathrm{wat}}$ represents the dry aerosol particle distribution. To better understand this unique aspect of the model (i.e., the simulated wet aerosol distribution becomes a 2D function of $m$ and $\left.m_{\mathrm{AP}, N}\right)$ see Fig. 2. Figure 2 shows one example of a wet aerosol size distribution simulated by EXMIX model. The number dis- tribution of ice crystals $f_{\text {ice }}\left(m, m_{\mathrm{AP}, N}\right)$ is given by the same variables. However, $m$ represents the mass of ice crystal, here again we only used one chemical composition for the aerosol particles for that study.

We consider that aerosol particles grow by condensation, can act as ice nuclei, and can be scavenged by ice crystals. We also consider that ice crystals grow by deposition, are formed through homogeneous and heterogeneous nucleation, and can collide and collect aerosol particles and ice crystals. Both number distributions $f_{\text {wat }}$ and $f_{\text {ice }}$ are thus calculated by numerical integration of the following two equations:

$$
\begin{aligned}
& \frac{\partial f_{\mathrm{wat}}\left(m, m_{\mathrm{AP}, N}\right)}{\partial t}=-\frac{\partial}{\partial m}\left[\left.f_{\mathrm{wat}}\left(m, m_{\mathrm{AP}, N}\right) \frac{d m}{d t}\right|_{\mathrm{wat}}\right]-f_{\mathrm{wat}}\left(m, m_{\mathrm{AP}, N}\right) J_{\mathrm{het} / \mathrm{hom}} \\
& -\int_{m_{0 \text { crys }}}^{\infty} f_{\text {wat }}\left(m_{\text {drop }}, m_{\mathrm{AP}, N}\right) K\left(m_{\text {crys }}, m_{\text {drop }}\right) f_{\text {ice }}\left(m_{\text {crys }}, m_{\mathrm{AP}, N}\right) d m_{\text {crys }} \\
& \frac{\partial f_{\text {ice }}\left(m, m_{\mathrm{AP}, N}\right)}{\partial t}=-\frac{\partial}{\partial m}\left[\left.f_{\text {ice }}\left(m, m_{\mathrm{AP}, N}\right) \frac{d m}{d t}\right|_{\text {ice }}\right]+f_{\mathrm{wat}}\left(m, m_{\mathrm{AP}, N}\right) J_{\mathrm{het} / \mathrm{hom}} \\
& -\int_{m_{0 \text { drop }}}^{\infty} f_{\text {wat }}\left(m_{\mathrm{drop}}, m_{\mathrm{AP}, N}\right) K\left(m, m_{\mathrm{drop}}\right) f_{\text {ice }}\left(m, m_{\mathrm{AP}, N}\right) d m_{\mathrm{drop}} \\
& +\int_{m_{0 \mathrm{drop}}}^{\infty}\left[\int_{m_{0 \mathrm{crys}}}^{m_{\mathrm{crys}}} f_{\mathrm{wat}}\left(m_{\mathrm{drop}}, m_{\mathrm{AP}, N}\right) K\left(m_{\mathrm{crys}}^{*}, m_{\mathrm{drop}}\right) f_{\text {ice }}\left(m_{\text {crys }}^{*}, m_{\mathrm{AP}, N}\right) d m_{\text {crys }}^{*}\right] d m_{\mathrm{drop}} .
\end{aligned}
$$

The first term on the right-hand side of both equations describes the time evolution by vapor diffusion growth [see Pruppacher and Klett 1997, their Eq. (12-39)]. The growth rate $(d m / d t)_{\text {wat }}$ is used as given in Pruppacher and Klett [1997, from their Eqs. (13-26) to (13-27b)]. The depositional growth of ice crystals given by $(d m / d t)_{\text {ice }}$ is also calculated following Pruppacher and Klett [1997, their Eq. (13-76)]. Key parameters controlling $(d m / d t)_{\text {ice }}$ are ice supersaturation and crystal shape, which influence capacity and the mass-length relationship, the ice crystals are supposed to be columnar and the deposition coefficient is set to 1 when it is not mentioned any other way.

The loss of the wet aerosol particles due to their nucleation to form crystals is considered in the second term on the right-hand side of Eq. (2). Consequently, this process appears as a source term in the evolution for ice crystals in Eq. (3). The different nucleation rates used in this study for homogeneous nucleation, $J_{\text {hom }}$, and for heterogeneous nucleation, $J_{\text {het }}$, will be presented in the following section.

The last terms in both equations represent the sto- chastic removal of aerosol particles after collision and collection by ice crystals. We use the collection kernel $K$ given by Martin et al. (1980) and Wang and Wusheng (2000). To compute these terms we have adapted the numerical scheme proposed by Bott (2000) to solve the stochastic equation of collision and coalescence in the case of a two-dimensional particle size distribution.

We assume the composition of dry aerosol particles to be sulfuric acid in internal mixing with some inertial material as silicates.

For the numerical solution of Eqs. (2) and (3) a logarithmically equidistant mass grid is introduced, that is,

$$
m_{j+1}=\beta m_{j}, \quad j=1, \ldots, n,
$$

yielding the equally spaced logarithmic mass grid mesh, $\Delta \ln m_{j}=\Delta \ln m=\ln \beta$. Note that $n$ is the total number of grid points, which is 130 in our model for the first coordinate (i.e., the mass of the wet aerosol particles or the ice crystals) and 75 for the second coordinate (i.e., the mass of the dry aerosol particle that has served as the nucleus). In the present model $\beta=2^{1 / 2}$, yielding a 


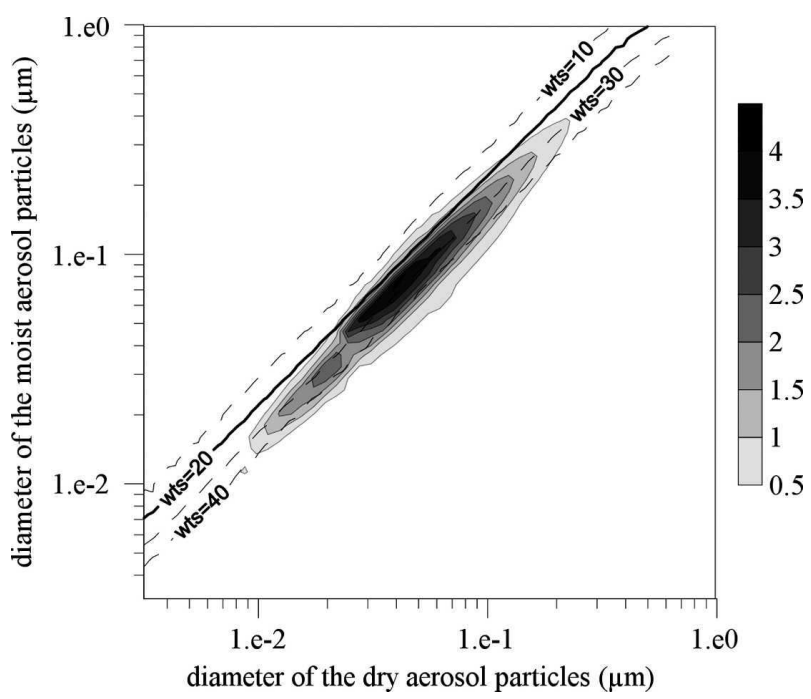

FIG. 2. Two-dimensional size distribution $\left(\mathrm{cm}^{-3}\right)$ for moist aerosol particles when the first ice crystals formed (shaded contours). Distribution of the weight percentage of sulfuric acid (dashed line). The thick line represents the value of $19.64 \%$, which is given by Clegg and Brimblecombe (1995) for the same thermodynamics conditions.

doubling of the particle mass after two grid cells. The mass of the first bin for both coordinates is the one of a pure sulfuric acid sphere with a radius of $1 \mathrm{~nm}$. Consequently, the mass of the last bin for the aerosol grid corresponds to a pure sulfuric aerosol particle of 5- $\mu \mathrm{m}$ radius. For the condensed particles (liquid or ice) grid, the mass of $0.1 \mathrm{~g}$ is reached in the last bin.

\section{c. Modeling of the nucleation process}

An important unresolved question is whether homogeneous or heterogeneous nucleation dominates the ice crystal formation. In an attempt to address this problem, we have introduced both these mechanisms into the model.

\section{1) Homogeneous nucleation}

The form of the theoretical homogeneous nucleation rate is given by Pruppacher and Klett [1997, their Eq. (7-51) for supercooled solution]:

$$
\begin{aligned}
J_{\text {hom }}= & 2 N_{c}\left(\frac{\rho_{\text {sol }} k T}{\rho_{\text {ice }} h}\right)\left(\frac{\sigma_{\text {ice/sol }}}{k T}\right)^{1 / 2} \exp \left(-\frac{\Delta F_{\text {act }}}{R T}-\frac{\Delta F_{g}}{k T}\right) \\
& \times V_{\text {sol. }}
\end{aligned}
$$

To form an ice crystal, two energy barriers must be overcome: $\Delta F_{\text {act }}$ is the activation energy and $\Delta F_{g}$ is the germ formation energy. The activation energy is approximated by the autodiffusion energy of water in solution since the difference in minimal potential energy between the ice and liquid phase can be neglected. It has, therefore, the following form [Pruppacher and Klett 1997, their Eq. (3-21)]:

$$
\frac{(\Delta F)_{\mathrm{act}, w}}{R} \approx \frac{d \ln \left(\frac{\eta_{w}}{T}\right)}{d(1 / T)},
$$

where $\eta_{w}$ is the viscosity of solution.

The germ formation energy is the energy the volume should gain to sustain its interface with the supercooled solution. This energy has the form of [Pruppacher and Klett 1997, their Eq. (7-52), from (6-51) to (6-58)]

$$
\begin{aligned}
\Delta F_{g} & =\frac{4 \pi}{3} \sigma_{\text {ice } / \mathrm{sol}} a_{g}^{2}, \quad \text { where } \\
a_{g} & =\frac{2 M_{w} \sigma_{\text {ice/sol }} / \bar{\rho}_{\text {ice }}}{\frac{2 M_{w} \sigma_{\text {sol/air }}}{r}\left(\frac{1}{\bar{\rho}_{\text {ice }}}-\frac{1}{\bar{\rho}_{\text {sol }}}\right)+\bar{L}_{m, 0} \ln \frac{T_{0}}{T}+R \bar{T} \ln a_{w}}
\end{aligned}
$$

$a_{g}$ is the germ radius; the terms with a bar are averaged between $T$ and $T_{0}$.

In Eqs. (4), (5), and (6), the solution properties appear through density, surface tension, water activity, and viscosity. Due to the variable chemical composition of the aerosol, these parameters are mostly unknown and need to be parameterized. To study the sensitivity of the results with respect to the chosen parameterization we have compared different parameterizations given in literature for the case of sulfuric acid aerosol particles. These are taken from Tabazadeh et al. (2000, hereafter $\mathrm{TAB}$, and references herein), DeMott et al. (1997, hereafter DEM), and Koop et al. (2000, hereafter KOO).

The approach of TAB is based on laboratory studies of surface tension, density, and activation energy for a solution of sulfuric acid. These values are fitted as a function of temperature and mass percentage $w_{t s}$. As our model concept with $f_{\mathrm{wat}}\left(m, m_{\mathrm{AP}, N}, x_{i}\right)$ directly provides $w_{t s}\left(=m_{\mathrm{AP}, N} / m\right)$ a further parameterization for $w_{t s}$ as used in TAB is not needed. Figure 2 shows isocontours for the mass fraction of sulfuric acid for the moist aerosol particles in the dashed lines as well as the moist aerosol particles 2D size distribution in shaded areas. The thick line is the value of the mass fraction for the same conditions according to Clegg and Brimblecombe (1995) as used in TAB. Figure 2 shows that with 
our treatment not all the moist aerosol particles have the same composition for the same initial size. This is the main difference between our treatment and other models that do not have a two-dimensional size distribution.

Solution density is computed with a polynomial function of temperature and mass percentage from a dataset provided by Myrhe et al. (1998):

$$
\rho_{\mathrm{sol}}=\frac{1}{1000} \sum_{i=0}^{10} A_{i} w_{t s}^{i} \quad \text { with } \quad A_{i}=\sum_{j=0}^{4} B_{i j} T\left({ }^{\circ} C\right)^{j}
$$

(coefficients of the polynomial function $B_{i j}$ are given in Myrhe et al. 1998). The surface tension of the icesolution interface is computed thanks to Antonoff's rule:

$$
\sigma_{\text {sol/ice }}\left(w_{t s}, T\right)=\left|\sigma_{\text {sol/air }}\left(w_{t s}, T\right)-\sigma_{\text {ice/air }}\right| \cdot
$$

The dataset from Sabinina and Terpugov (1935) is used to parameterize the surface tension of air-solution interface with the expression of

$$
\begin{aligned}
\sigma_{\text {sol } / \text { air }}= & 142.35-0.96525 w_{t s} \\
& -T\left(0.22954-0.0033948 w_{t s}\right) .
\end{aligned}
$$

Finally, energy of activation is derived from the experiment of Koop et al. (1998) on a polynomial form:

$$
\Delta F_{\mathrm{act}}=\sum_{i=0}^{8} A_{i} \times 10^{-12} \times w_{t s}^{i}
$$

(coefficients of the polynomial function $A_{i}$ are also given in TAB). Equations (7a)-(7d) are expressed in the centimeter-gram-second (CGS) system unit.

DEM follows the classical approach for homogeneous nucleation of pure water (Pruppacher and Klett 1997). For that approach, the effect of the solution is considered by the use of a so-called effective temperature, which corrects the droplet temperature by a freezing point depression, as first proposed by Sassen and Dodd (1989):

$$
T_{\text {eff }}=T+\lambda \Delta T_{m},
$$

where $\Delta T_{m}$ represents the extra cooling due to solution effects, which is needed for freezing. This cooling is a function of the molality, $\mu$, of the solution and is given in DEM with

$$
\begin{aligned}
\Delta T_{m}= & 3.513627 \mu+0.471638 \mu^{2}+0.033208 \mu^{3} \\
& +0.02505 \mu^{4},
\end{aligned}
$$

where $\lambda$ is an empirical parameter to account for additional change in the nucleation temperature due to the nonideality of the solution. This coefficient influences highly the nucleation efficiency. We assumed it equals to 2 following Lin et al. (2002).

KOO found from laboratory studies that the homogeneous nucleation rate is independent of the solute nature of the aerosol and depends only on water activity. Thus, the only variables for this approach of the nucleation rate are temperature and water activity of the solution:

$$
\begin{aligned}
\log \left(J_{\mathrm{hom}}\right)= & -906.7+8502 \Delta a_{w}-26924\left(\Delta a_{w}\right)^{2} \\
& +29180\left(\Delta a_{w}\right)^{3} \\
\Delta a_{w}(c, T)= & a_{w}\left(c^{\mathrm{eff}}, T\right)-a_{w}^{i}(T), \\
a_{w}^{i}(T)= & \exp \{[210368+131.438 T-3.32373 \\
& \left.\left.\times 10^{6} T^{-1}-41729.1 \ln (T)\right] \times 10^{7} / R T\right\},
\end{aligned}
$$

where $a_{w}\left(c^{\text {eff }}, T\right)$ is the water activity of the solution and $a_{w}^{i}(T)$ is the water activity of solution in equilibrium with the ice phase.

\section{2) Heterogeneous nucleation}

Even if theoretical expression for heterogeneous nucleation is available in the literature (Jensen et al. 1994; Khvorostyanov and Curry 2000), we could not find any dataset to solve each variable in this expression. That is why we used empirical approaches of Meyers et al. (1992, hereafter MEY), DEM97, and DeMott et al. (1998, hereafter DEM98), which are based on field or laboratory experiments.

The parameterization of MEY only needs the knowledge of the ice supersaturation $s_{v, i}$ and is given by

$$
N_{\text {IN }}=10^{-3} \times \exp \left(-0.639+12.96 \times s_{v, i}\right) .
$$

The MEY parameterization gives only a number of activated ice nuclei at a given ice supersaturation ratio, but does not provide any information about the size of the ice nuclei. We assumed that all aerosol particles, whatever their size, nucleate with the same efficiency.

The approach DEM97, similar to their approach for homogeneous nucleation, uses an effective temperature. In addition, this parameterization takes the surface of the insoluble soot particles into account, implying that the nucleation rate of insoluble particles increases with size:

$$
N_{\text {IN }}=1.04 \times 10^{-4} \times 4 \pi r_{\text {soot }}^{2} \times\left(T-T_{\text {eff }}\right)^{7.767} .
$$




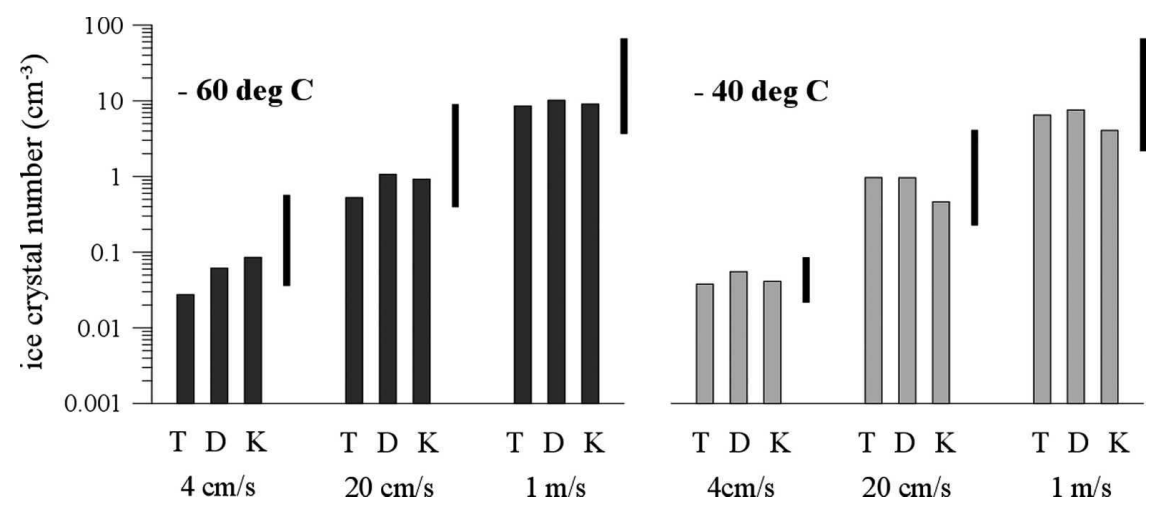

FIG. 3. Total number of ice crystals formed by homogeneous nucleation using different vertical updraft velocities, $w$, and different nucleation rates from TAB (T), KOO (K), or DEM (D). The black bars represent the range of results found in Lin et al. (2002) for the same scenarios.

In that case we assumed that the insoluble part of the aerosol particles is a sphere composed of soot with a density of $1.84 \mathrm{~g} \mathrm{~cm}^{-3}$.

The third approach for heterogeneous nucleation (DEM98) is mainly based on aircraft observations in cirrus clouds. DEM98 found a strong correlation between the number of ice crystals and the number of cloud nuclei, $N_{\mathrm{AP}}$, which is the number of particle greater than $12 \mathrm{~nm}$ measured in clear air. This parameterization for ice nuclei also takes the effective temperature into account.

$$
N_{\text {IN }}=N_{\text {AP }} \times 1.3 \times 10^{-23} \times\left(T-T_{\text {eff }}\right)^{11.75} .
$$

\section{Investigations on ice crystal number concentrations}

\section{a. Nucleation rate studies}

The three parameterizations for homogeneous and heterogeneous nucleation have been tested in the dynamical frame of the air parcel model. The model results are compared with those of Lin et al. (2002). Following their recent comparative study on detailed cirrus models, we investigated the following two scenarios: a cold-air case, where the air parcel starts at $170 \mathrm{hPa}, T=$ $-60^{\circ} \mathrm{C}$, and $\mathrm{RH}_{i}=100 \%$, and a warm-air case starting at $340 \mathrm{hPa}, T=-40^{\circ} \mathrm{C}$, and $\mathrm{RH}_{i}=100 \%$. To be consistent with the study of Lin et al. (2002), we assumed aerosol particles to be pure sulfuric acid in the case of homogeneous nucleation and their distribution to consist of a single-mode lognormal distribution with a total number of particles of $200 \mathrm{~cm}^{-3}$, a mean radius of 20 $\mathrm{nm}$, and a standard deviation of 2.3. To compute how moist the aerosol particles are, we assumed they are initially at equilibrium with their environment and we use the Köhler equation. The resulting ice crystals were assumed to be spherical. More details on the dynamical and microphysical model setup are given in Lin et al. (2002).

\section{1) Homogeneous NUCLEATION ONLY}

Figure 3 presents the results for the modeled ice number concentration after a vertical ascent of $800 \mathrm{~m}$. The results for the cold-air case are displayed on the left-hand side; the ones for the warm-air case are on the right-hand side. Each case was run for a vertical wind speed of 4, 20, and $100 \mathrm{~cm} \mathrm{~s}^{-1}$. For each case and each updraft speed, three different rates for homogeneous nucleation [see section $2 b(1)]$ were compared. The elevated black bar for each case and each updraft velocity gives the range of the results found in Lin et al. (2002) for the same parcel studies. TAB, DEM, and KOO compared seven numerically different detailed cirrus models, which essentially used the same three parameterizations for homogeneous nucleation. However, each used its own numerical air parcel framework.

Figure 3 shows that the number of ice crystals formed increases significantly with the intensity of the vertical wind. The reason for this behavior results from the increase of the maximum in ice supersaturation with increasing vertical wind speed (see Table 1). We also note that the influence of the air temperature on ice crystal production is less pronounced. In our study, a number increase for the cold-air case only becomes visible for the highest updraft speed of $1 \mathrm{~m} \mathrm{~s}^{-1}$ and this increase is of the same order of magnitude as the numerical variability of our results. If we compare our results with the ones of corresponding models using TAB, DEM, or KOO in Lin et al. (2002), we can see some significant 
TABLE 1. Maximum ice supersaturation (\%) calculated for the different schemes of homogeneous nucleation.

\begin{tabular}{|c|c|c|c|c|c|c|}
\hline \multirow{2}{*}{$\begin{array}{l}\text { Nucleation } \\
\text { schemes }\end{array}$} & \multicolumn{3}{|c|}{ Cold-air cases } & \multicolumn{3}{|c|}{ Warm-air cases } \\
\hline & $4 \mathrm{~cm} \mathrm{~s}^{-1}$ & $20 \mathrm{~cm} \mathrm{~s}^{-1}$ & $100 \mathrm{~cm} \mathrm{~s}^{-1}$ & $4 \mathrm{~cm} \mathrm{~s}^{-1}$ & $20 \mathrm{~cm} \mathrm{~s}^{-1}$ & $100 \mathrm{~cm} \mathrm{~s}^{-1}$ \\
\hline TAB & 43.4 & 52.8 & 67.2 & 41.6 & 44.5 & 46.2 \\
\hline KOO & 46.4 & 48.1 & 50.3 & 41.8 & 43.0 & 44.4 \\
\hline DEM & 48.7 & 49.6 & 51.9 & 42.1 & 42.9 & 44.9 \\
\hline
\end{tabular}

differences for particular cases. Figure 2 gives one of the main explanations for this difference in the particular case of a comparison of our use of the parameterization of TAB and its original use in Lin et al. (2002). In this figure, a small number of our moist particles have a weight percentage lower than in the Clegg and Brimblecombe (1995) case, which is used in TAB. Even though there are very few, these more dilute aerosol particles could cause a large difference in the ice crystal concentration, because they will nucleate earlier and perhaps will be numerous enough to prevent humidity reaching higher values.

The dependence of number concentration on the three nucleation rates TAB, KOO, and DEM shows two different behaviors. For cases with $w \geq 20 \mathrm{~cm} \mathrm{~s}^{-1}$, or in other words for median and high updraft velocities, the employed parameterization typically differ by a factor of 2 in ice crystal concentration. This factor is significantly smaller than in the study of Lin et al. (2002) where these three parameterizations were used within one of seven individual numerical cloud models. Lin et al. (2002) also came to the conclusion that their variability does not entirely come from the use of a different nucleation rate but also from the use of a different numeric in their models. Here we compare these three parameterizations in a unique numerical cloud model wherein only the rate of ice nucleation varied. Another reason, for which we decrease a lot the variability found in Lin et al. (2002), is our continuous treatment of aerosol particles immerged in solution droplets, which allow us to not assume the composition of solution droplets. In contrast, many types of aerosol treatments in various models were presented in Lin et al. (2002). Our variability is so low that we can even conclude that for moderate to high updraft velocity the number of ice crystal formed is almost insensitive to the nucleation rate used. However what is really surprising in our result is that this conclusion does not stand for weak updraft. Our range of variability, in those cases, for the ice number concentration is similar and even slightly larger to that in Lin et al. (2002), ranging from a factor of 5 to more. Thus, we can conclude that only for weak updraft will the choice of a particular parameterization for solution effects be of great importance.
Further conclusions from this figure are not obvious because no general tendency appears from it. We notice from cases with weak updrafts that the parameterization in TAB always gives the smallest ice crystal numbers. The same statement holds for all updraft conditions in the cold-air case (below $-60^{\circ} \mathrm{C}$ ), but is not valid in the warm case for higher updrafts. To better understand the behavior of the different nucleation rates, in Fig. 4 we display the homogeneous nucleation rate $J_{\text {hom }}$ as a function of the ice supersaturation for a small (radius $=40 \mathrm{~nm}$ ) and a medium size aerosol particle $(200 \mathrm{~nm})$.
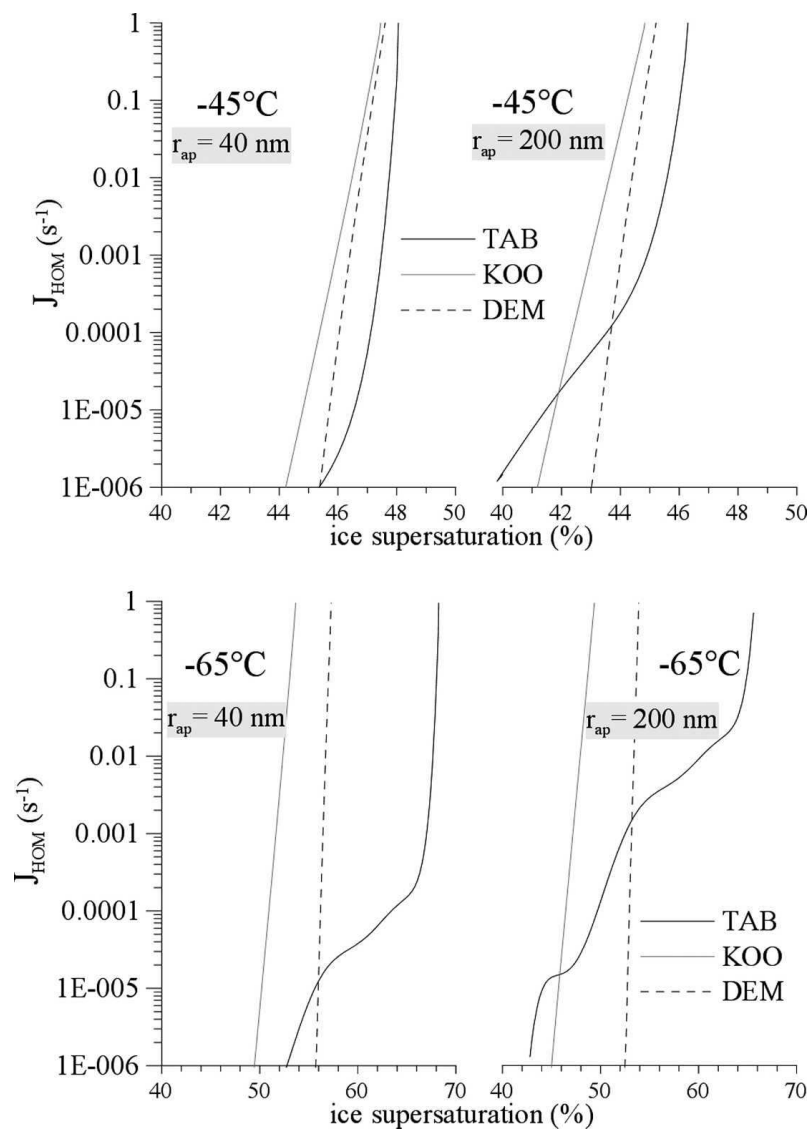

FIG. 4. Homogeneous nucleation rate, $J_{\text {hom }}\left(\mathrm{s}^{-1}\right)$, as a function of ice supersaturation for two temperatures, two different aerosol particle sizes, and the three nucleation schemes TAB, KOO, and DEM. 
In Fig. 4, temperatures are respectively $-45^{\circ}$ and $-65^{\circ} \mathrm{C}$ for the warm- and cold-air case because $5^{\circ} \mathrm{C}$ is roughly the cooling needed before nucleation to occur in the air parcel. From Fig. 4, we can detect that large solution droplets start to nucleate at smaller supersaturation than the small ones. Because they are larger, their curvature effects are weaker and they can grow by condensation faster. The dilution of the salt will be the more efficient and the nucleation easier. In addition, we notice that the homogeneous nucleation needs at cold temperature larger ice supersaturation and in DEM is the most sensitive scheme to that temperature dependency. In all the cases, DEM is also the scheme that provides the greater slope for $d J_{\mathrm{hom}} / d \mathrm{RH}_{i}$. DEM and $\mathrm{KOO}$ parameterizations do not show big variation in this slope for increasing ice supersaturation; $\mathrm{TAB}$ on the other hand shows the weakest slope and the slope the most sensitive to the ice supersaturation. This shows that one cannot explain the difference of efficiency of these three schemes to form ice crystals by the time duration of the nucleation event. For the TAB scheme, a longer nucleation event means a greater difference in the maximum ice supersaturation and ice supersaturation at the cloud base. However, since this slope is so weak, it does not mean that the TAB scheme could reach the regime of very high homogeneous nucleation rates.

\section{2) Homogeneous and heterogeneous NUCLEATION}

Figure 5 shows the evolution of ice supersaturation, ice water content, and ice crystal concentrations as a function of time (i.e., the altitude of the ascending air parcel), considering the scenario of the warm-air case with a vertical velocity of $20 \mathrm{~cm} \mathrm{~s}^{-1}$. The comparison is done for homogeneous (Fig. 5a), heterogeneous (Fig. $5 \mathrm{~b}$ ), and heterogeneous plus the TAB homogeneous nucleation (Fig. 5c). To be able to describe heterogeneous nucleation we assumed that the aerosol particle is an internal mixing of sulfuric acid and some inert material like soot or silicate. The acid part is assumed to be $50 \%$ of the total mass.

We defined, following Lin et al. (2002), the cloud base as the altitude for which the threshold of one ice particle per liter is reached. We can see, in Fig. 5a, that for homogeneous nucleation the choice of the nucleation parameterization does not change the cloud base. The three schemes need at least $40 \%$ of supersaturation before forming ice, the maximum supersaturation varies only within $2 \%$ (see Table 1). Despite this small variability, the final variance in the number of crystals is quite important, with only 573,1020 , and $1280 \mathrm{~L}^{-1}$ for
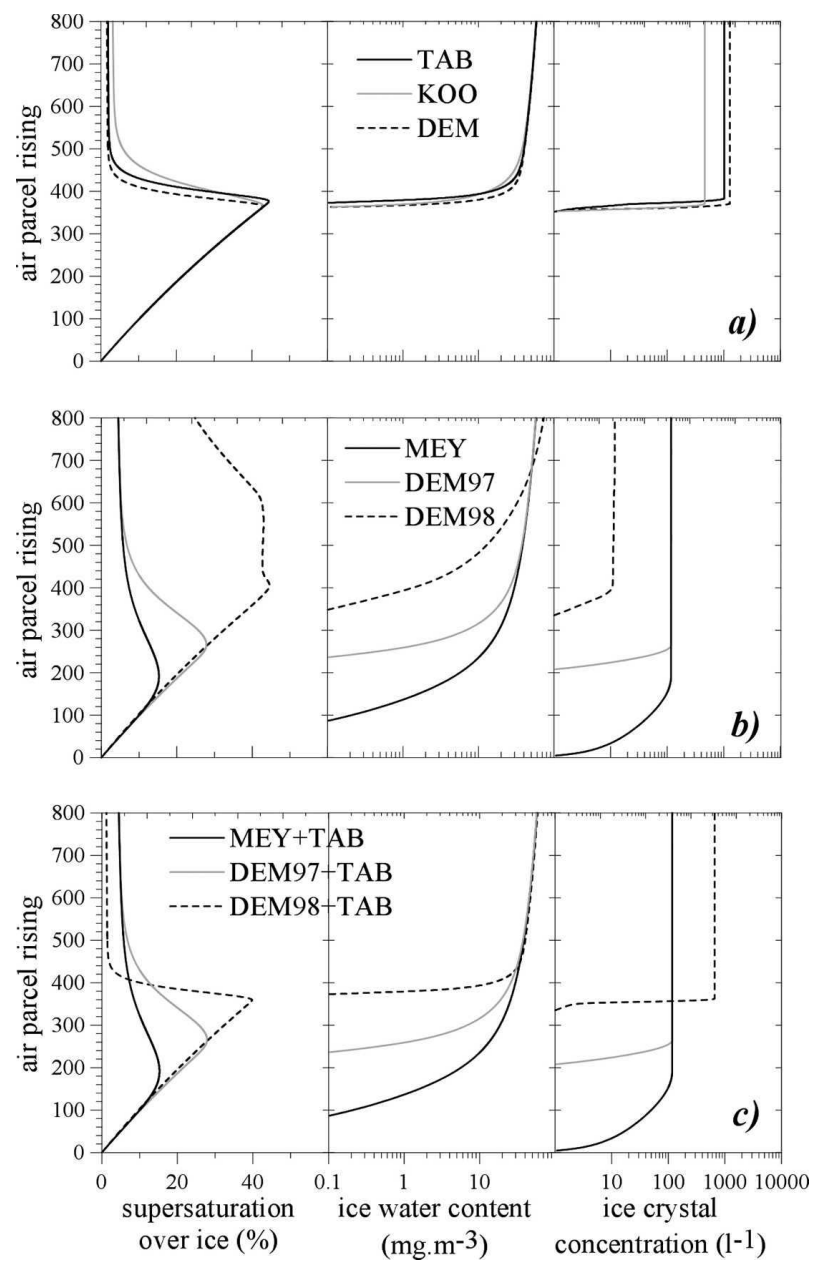

FIG. 5. Evolution along the air parcel height in $\mathrm{m}$ of the (left) ice supersaturation (\%), (middle) the total ice water content (mg $\mathrm{m}^{-3}$ ), and (right) the ice crystal concentration $\left(\mathrm{L}^{-1}\right)$. Comparison of the different nucleation scheme for (a) homogeneous nucleation only (i.e., TAB, KOO, and DEM), (b) heterogeneous nucleation only (i.e., MEY, DEM97, and DEM98), (c) and the three parameterizations for heterogeneous nucleation together with the TAB approach for homogeneous nucleation. All these runs are performed in the scenario denoted warm with an ascent of 20 $\mathrm{cm} \mathrm{s}^{-1}$ in Lin et al. (2002).

KOO, TAB, and DEM, respectively. We notice that the time interval during which nucleation is active is quite short since the process becomes inactive within a few tens of meters. And as we mentioned with the analysis of Fig. 4 the length of the time during which nucleation is active is not directly linked to the final number of ice crystals. Nucleation events with the DEM and KOO scheme are almost of the same duration and their final ice crystal concentrations differ by a factor greater than 2 .

In Fig. $5 b$, considering only heterogeneous nucleation, we notice the totally different behavior of the 
DEM98 formula. This parameterization is quite inefficient to form ice crystals (only $12 \mathrm{~L}^{-1}$ ). The evolution of the ice supersaturation is, therefore, explained by the lack of ice crystals. They are, indeed, not numerous enough to consume the vapor, thus the saturation over liquid water level is reached and some droplets are formed, which is unrealistic. For the two other parameterizations, heterogeneous nucleation is more active but final ice crystal concentrations remain small compared to the one from the simulation with homogeneous nucleation (117 and $118 \mathrm{~L}^{-1}$ for $\mathrm{MEY}$ and DEM97, respectively). Since the parameterization of MEY depends only on saturation over ice, nucleation begins at the initial altitude of the air parcel. The cirrus cloud base is, therefore, near the initial altitude. The air parcel rises roughly $200 \mathrm{~m}$ before producing the maximum of ice crystals possible at this temperature. For DEM97, cirrus cloud formation differs, as it takes into account the effective temperature; hence, the sulfuric solution, with its insoluble core, needs to be sufficiently diluted before nucleation occurs. Thus, the cirrus cloud base is located about $200 \mathrm{~m}$ above the initial altitude. Nucleation starts at smaller dilution than for homogeneous nucleation. The ice supersaturation at the cirrus cloud base for DEM97 is only $29.5 \%$ compared to $40.1 \%$ for DEM in the homogeneous case (Fig. 5a).

After these considerations, we can anticipate that considering both homogeneous and heterogeneous nucleation together in that scenario will be similar to only considering heterogeneous nucleation. Ice crystals formed primarily through the heterogeneous process will, by vapor diffusion, prevent an increase of ice supersaturation to values needed for homogeneous nucleation. Figure $5 \mathrm{c}$ substantiates this statement. We note that the two curves for the MEY and DEM97 parameterizations stay unchanged even if the TAB approach for homogeneous nucleation is simultaneously considered. For the DEM98 parameterization, which was shown to be really inefficient in forming ice crystals, the threshold for homogeneous nucleation in ice supersaturation could be reached. Although the number of ice crystals formed by heterogeneous nucleation is quite small, they are sufficient to decrease the maximum ice supersaturation from $44.5 \%$ (for TAB only) to $39.8 \%$ (for DEM98 and TAB). The final number in ice crystals is hence smaller considering both nucleations together (659 $\mathrm{L}^{-1}$ ) than considering homogeneous nucleation alone $\left(1020 \mathrm{~L}^{-1}\right)$. For this scenario we can then conclude that considering heterogeneous nucleation from DEM97 or MEY will prevent homogeneous nucleation to be active. One can argue that this result depends on the vertical velocity and does not apply for stronger updraft. But repeating that test for the case with $1 \mathrm{~m} \mathrm{~s}^{-1}$, we also found that the maximum ice supersaturation reached if heterogeneous nucleation is active is lower than the ice supersaturation needed for homogeneous nucleation to occur.

\section{b. Implications for comparisons with the INCA measurements}

During the INCA campaign, a total of 19 scientific missions representing more than 130 flight hours, several types of cirrus were sampled, including frontal (cold and warm) cirrus, jet stream cirrus, cirrocumulus, orographic wave cirrus, and anvil blow-off cirrus. To focus on pure ice clouds, only measurements taken at air temperature below $235 \mathrm{~K}$ were analyzed. The sampling approach has been described in Kärcher and Ström (2003) and Gayet et al. (2004). The cirrus clouds systems were chosen to be young. The flight procedures mostly consisted of climbing to high altitudes above the main cloud layer and then performing several 10-15min flight legs at different levels within the cloud. These procedures allow for the study of the upper cloud layers, which are regions of formation for the cirrus clouds.

In Kärcher and Ström (2003) distributions of occurrence of vertical velocity, temperature, aerosol particles, and ice crystal concentrations are presented for both PR and PA campaigns. From their Fig. 2, we note that, for the ice crystal concentration, the range from 1 to 10 ice crystals $\mathrm{cm}^{-3}$ is densely populated. From our theoretical modeling, we can conclude that the most likely nucleation process to get such high concentrations of ice crystals is the homogeneous nucleation considered alone. This statement is in agreement with other conclusions from theoretical modeling (Lin et al. 2002). Indeed, the number of crystals formed by the heterogeneous nucleation parameterizations used is at least one order of magnitude smaller. If we consider the two processes together, the regime of homogeneous nucleation will not be reached, except for DEM98, since the ice crystals formed at smaller supersaturation by heterogeneous nucleation consume the water vapor. In addition, even if the heterogeneous nucleation scheme allows homogeneous nucleation to be reached the ice crystal concentrations are then smaller. Consequently, in order to explain the INCA measurements with the model, based on the parameterizations we used for homogeneous and heterogeneous nucleation, homogeneous nucleation needs to be active alone.

In addition, our theoretical results, summarized in Fig. 3, show that homogeneous nucleation could form high ice crystal concentration in agreement with the INCA measurements, but only for vertical velocities 
between 20 and $100 \mathrm{~cm} \mathrm{~s}^{-1}$ at both temperatures. Distributions of occurrence of vertical velocity shown in Kärcher and Ström (2003) are unable to reproduce this peak in ice crystal concentration distribution assuming homogeneous nucleation. Temperature sampling during the INCA campaign is in the range between 215 and $235 \mathrm{~K}$, which is roughly that of our theoretical work and in which our model did not show any sensitivity to temperature. Kärcher and Ström (2003) also showed that the sensitivity of final ice crystal concentration to temperature is very low and unable to explain the observed ice crystal concentration assuming homogeneous nucleation. So we cannot superimpose a variation in temperature to the observed variability in updraft speed to explain the peak of ice crystal concentration observed in the range of $1-10 \mathrm{~cm}^{-3}$. Kärcher and Ström (2003) almost reproduced the observed ice crystal concentration distribution by adding to the vertical velocities a random component between 0 and 20 $\mathrm{cm} \mathrm{s}^{-1}$, implying a net increase of $5 \mathrm{~cm} \mathrm{~s}^{-1}$ to the mean value of the updraft speed. Increased dynamics variability could then be the answer to producing high ice crystal concentrations with weak updrafts, but the treatment of microphysics should also be investigated.

The ice crystal concentrations of our modeling studies are controlled by the competition for water vapor between the solution droplets and the newly formed ice crystals. The competition is the result of the droplets needing really high supersaturation to homogeneously nucleate and the fast growth of the newly formed ice crystals by deposition. To form a greater number of ice crystals, one would need to maintain for longer time a high ice supersaturation and therefore to slow down the water vapor consumption by ice crystal diffusional growth. To vary the shape of ice crystals will vary their capacitance and consequently their growth rate (Pruppacher and Klett 1997). However, differences in the growth rates of hexagonal plates, columns, or ice spheres can only change the ice crystal number by a maximum of $150 \%$, and moreover the spherical shape, which was assumed to be consistent with the study of Lin et al. (2002), is the one that gives the highest concentrations. Consequently, a different shape cannot resolve the observed discrepancies. As another possibility, we can study the impact of the vapor deposition accommodation coefficient. As Gierens et al. (2003) have shown, an accommodation coefficient of unity makes the model underestimate the ice crystal concentration. Moreover, they obtained ice crystal numbers in agreement with the INCA campaign for low vertical velocities very commonly sampled $\left(15 \mathrm{~cm} \mathrm{~s}^{-1}\right.$ in their work) by considering this coefficient to be small, at least for small ice crystals. One of the reasons considered in Gierens et al. (2003) to explain the small accommodation of small ice crystals is the impurity of the ice surface. Some new experimental evidence for this impurity has been performed. In their work, Ettner et al. (2004) observed freezing of sulfuric acid solution droplets with densities commonly encountered in the upper troposphere. These observations showed at freezing point the instantaneous ejection of the particular content of solution droplets to the surface. Aerosol fragments then contaminate the ice crystal surface at its earliest stage. One might speculate that these debris pieces could decrease the water accommodation coefficient for small ice crystals.

Finally, a very low accommodation coefficient for micron-sized ice crystals is very probable with regard to recent experiments and could explain the numerous occurrences of high ice crystal concentrations with the observed vertical velocity distribution.

\section{Investigations of residual aerosol particle spectra}

Another helpful method for the assessment of the different parameterizations of the nucleation mechanisms is the analysis of measurements of the particles that remain after the ice crystals have been evaporated. There are two different mechanisms to incorporate aerosol particles inside the ice crystal. There is the nucleation and here we assumed that the aerosol content of the droplet remains in the formed ice crystal during nucleation. There is also the possibility that wet aerosol particles free in the air could be impacted by an ice crystal and stick on it. The modeling concept for ice crystals presented by Eq. (3) treats explicitly the nucleus mass $m_{\mathrm{AP}, N}$ and therefore allows for the calculation of the "residual" particle spectra.

\section{a. Incorporation of aerosol particles in ice phase by nucleation}

In the idealized scenario of the warm-air case with $w=20 \mathrm{~cm} \mathrm{~s}^{-1}$, which was presented in previous section, we investigated how homogeneous nucleation incorporates aerosol particle in the ice phase. Results for the three different schemes TAB, KOO, and DEM are displayed in Fig. 6a. The graph for the three residual spectra reflects the nucleation behavior already discussed in Fig. 4. Large particles will nucleate ice at smaller supersaturation than small particles; thus, most large particles serve as ice nuclei while the small ones are not nucleated. The difference between the effec- 


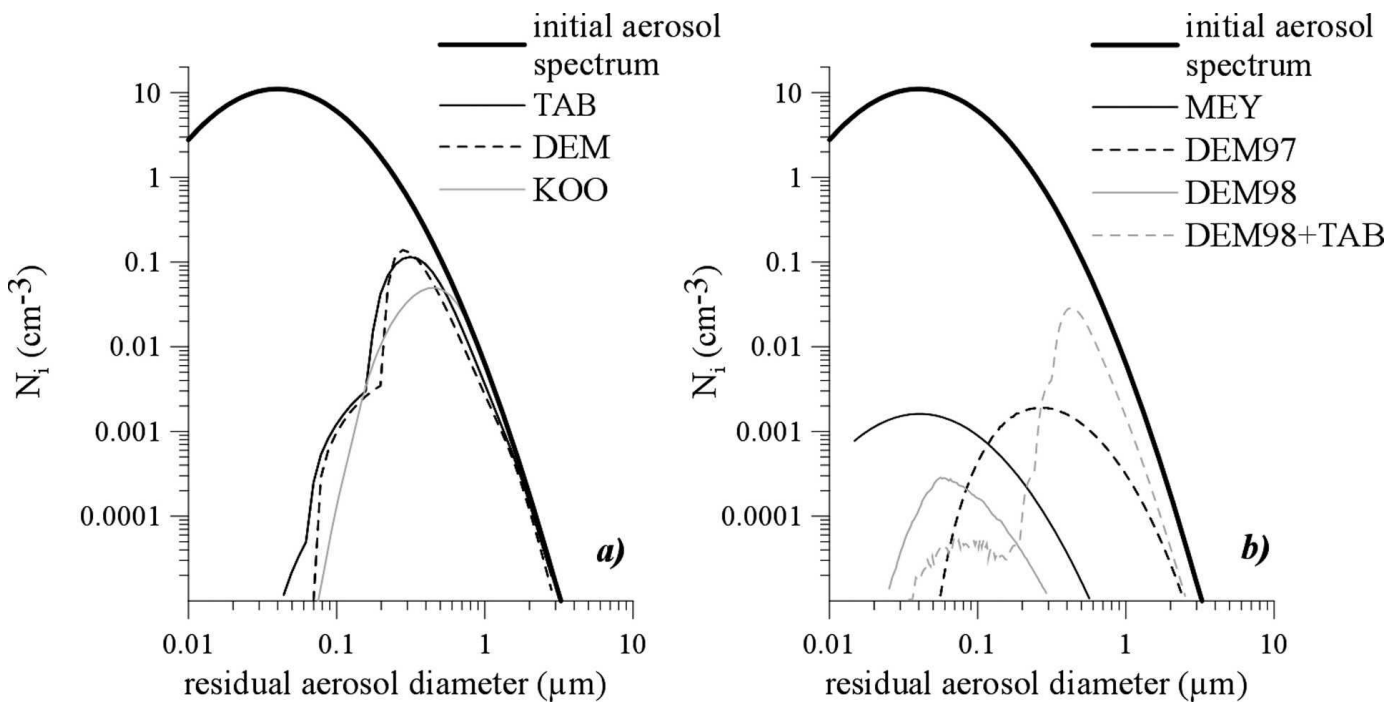

FIG. 6. Modeling results for number distribution of residual particles using a lognormal distribution for the ambient aerosol particle spectrum. Here $N_{i}$ is the concentration in the $i$ th model bin when $i$ goes from 1 to 75 for (a) the homogeneous nucleation rates TAB, DEM, and $\mathrm{KOO}$ and (b) for the heterogeneous nucleation rates only MEY, DEM97, and DEM98, as well as for DEM98 heterogeneous together with the TAB homogeneous parameterization.

tiveness of small and large particles is so pronounced that we can even define a sort of cut-sized diameter in Fig. 6a for each parameterizations. For KOO, since the slope of the nucleation rate as a function of humidity was not really steep, the cut-sized diameter for nucleation is not so sharp. The slopes for TAB and DEM of nucleation rate as a function of humidity are different. It is much less steep for TAB. This can explain how, even with forming less ice crystals, TAB could nucleate smaller aerosol particles.

Figure $6 \mathrm{~b}$ provides the equivalent results for the three heterogeneous nucleation parameterizations: DEM97, DEM98, and MEY. The preference to nucleate large particles remains only visible for the DEM97 approach. Equation (11) shows that there are two reasons for this: first, the soot surface is taken into account. Consequently, increasing the aerosol particles sizes also increases the nucleation rate. Second, effective temperature is considered. Thus, for large particles the curvature effects are weaker, the particles grow more readily and are more dilute and the nucleation rate is greater. The MEY parameterization nucleates all particle size with the same efficiency since the nucleation rate [Eq. (10)] only depends on the ice supersaturation. A size dependency for the heterogeneous nucleation rate for DEM98 also exists in Eq. (12) (hidden in $T_{\text {eff }}$ ), however, this cannot be detected in Fig. $6 \mathrm{~b}$ due the weak nucleation efficiency.

As explained in the previous section, if homogeneous and heterogeneous nucleations are active together in the air parcel, the MEY plus DEM97 parameterization results are the same as if heterogeneous nucleation is considered alone. On the contrary, for a combination of DEM98 with one of the homogeneous schemes TAB, DEM97, or KOO, both nucleation regimes could be reached. The results for DEM98 and TAB are provided in Fig. $6 \mathrm{~b}$ and underline this statement since two different modes are visible in the modeled residual aerosol distribution. The one at the smaller size is due to heterogeneous nucleation and the bigger one is due to homogeneous nucleation.

\section{b. Incorporation of aerosol particles in ice phase by collection}

Through Brownian motion, phoretic effects and inertial impact ice crystal can collide with a wet aerosol particle and collect it. The aerosol particle content of that solution droplet will then be incorporated into the ice phase.

The importance of the uptake of wet aerosol particles by ice crystals have been estimated in the air parcel framework for the warm-air case with a vertical velocity of $20 \mathrm{~cm} \mathrm{~s}^{-1}$. Nucleation is assumed to be homogeneous and solution effects are taken into account through the TAB parameterization. After 30 min of modeling, our study showed that the cirrus cloud reached a typical ice water content as well as a typical ice crystal concentration. At this point, less than $1 \%$ of the mass of residual aerosol came from the collision and collection pro- 
cesses. With a purpose of studying the removal of upper-tropospheric aerosol by cirrus clouds, collection is thus negligible compared to nucleation in the formation region of the cirrus cloud. Moreover, only one part in $10^{8}$ of the ice water content was coming from this process, compared to the one in $10^{5}$ from nucleation, indicating that the uptake of aerosol particles by falling ice crystals is also obviously negligible to explain the size of ice crystals and therefore ice water content. This small impact of the collision and collection process is not a result of the particular efficiency dataset from Martin et al. (1980) and Wang and Wusheng (2000), but more of the very small concentration of ice and aerosol particles. Indeed, setting all efficiencies to the value of 1 , as a crude test, leads to the same conclusions.

\section{c. Implications for comparisons with the INCA measurements}

Measurements of ambient and residual aerosol particles were performed (Seifert et al. 2004) during the INCA campaign. The residual aerosol particles are analyzed downstream of the CVI inlet, which separates cloud elements with an aerodynamic size between 5 and $60 \mu \mathrm{m}$ from the surrounding atmospheric air, after evaporation of the cloud elements. Downstream of the inlet, for one branch the sampled particles are at a temperature of $25^{\circ}-30^{\circ} \mathrm{C}$. We assume that the aerosol particle size distribution that was measured in that branch is the size distribution of residual aerosol particles. The number of residual aerosol particles has been shown to be in agreement with the number of ice crystal (Seifert et al. 2003). This makes the assumption that each ice crystal leaves behind only one particle to be valid. But, there is no evidence that the remaining aerosol particle after evaporation corresponds exactly to the initially dry aerosol particle that has served as the nucleus for the solution droplet, which has nucleated. However, no information is available on the fraction of aerosol particles that has been lost from the entering in the ice phase until the analysis. In that case, we assumed the mass of the initial dry aerosol particles, $m_{A P, N}$, to be directly comparable to the mass of sampled aerosol particles downstream of the CVI inlet in the $25^{\circ}-30^{\circ} \mathrm{C}$ branch.

Figure 7 shows results from 31 March in PA and 27 September in PR. Both pairs of measurements suggest that small aerosol particles have the capacity to be ice nuclei. This holds for all measurements taken (J. Ström 2003, personal communication). A comparison of the homogeneous nucleation model results for the ice crystal residual particles with those measured during the INCA experiment in cirrus clouds points out a dramatic

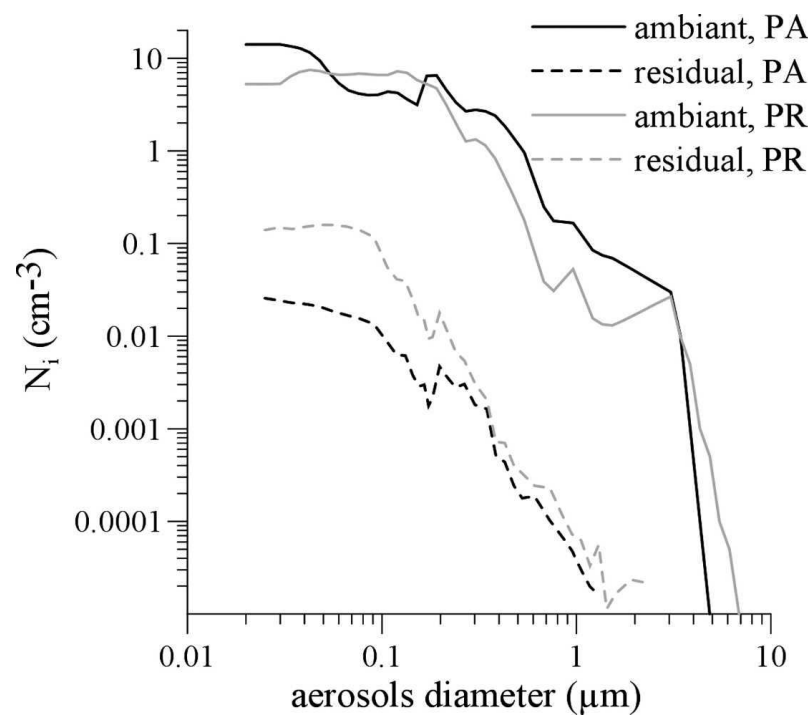

FIG. 7. Measurements of the ambient and residual aerosol number distributions performed on 31 March on PA and on 27 September on PR, $N_{i}$ is the concentration in the $i$ th DMPS bin.

discrepancy in the shape of the size dependence. Observations in cirrus clouds for the Northern and Southern Hemisphere do not confirm a stronger nucleation efficiency for the larger aerosol particles but show rather that smaller particles are more effective as the ice nucleus. Indeed, comparison of these measurements with the modeled residual spectra for the homogeneous nucleation process (Fig. 6a) suggests that all three homogeneous nucleation schemes strongly overestimate the nucleation of large aerosol particles and strongly underestimate the nucleation of small particles. We cannot incriminate the possible difference from the initial dry aerosol particles, which formed an ice crystal and the remaining analyzed aerosol particles to be the only cause of that discrepancy even though it could explain some of it. One possible explanation for the discrepancy with the observations could be that it is not the homogeneous but the heterogeneous that dominated nucleation during INCA, which is in disagreement with our conclusions from the previous section. Without a proper case study further analyses are impossible.

\section{Investigations of particle size distribution}

If one wants to quantify the radiative properties of cirrus clouds or their role in upper-tropospheric chemistry, it is necessary to correctly describe the number size distribution of the ice crystals. Figure 8 provides a particular ice crystal distribution observed with an FSSP (length smaller than $20 \mu \mathrm{m}$ ) and a 2DC probe 


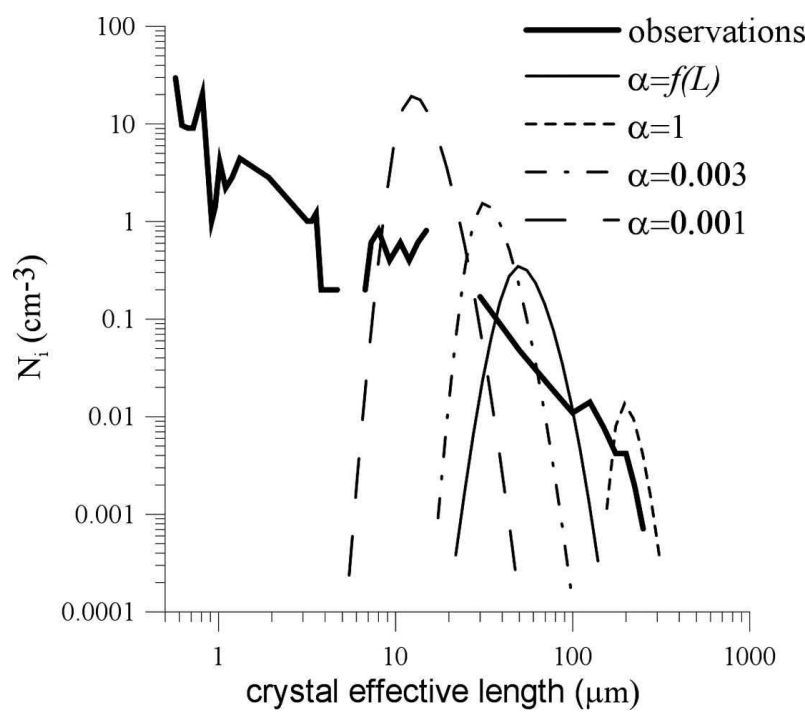

FIG. 8. Comparison of one typically observed ice crystal size distribution during the INCA campaign with some of the modeled distributions obtained by Gierens et al. (2003) and shown in their work in Fig. 2.

(length larger than $25 \mu \mathrm{m}$ ) during the INCA campaign in an upper region of the cirrus cloud to represent the formation region of this cloud. Figure 8 also shows one modeled ice crystal spectrum from the study of Gierens et al. (2003) using an air parcel. The figure demonstrates that even if a detailed microphysics model can produce ice crystal number and ice water content in agreements with observations, there is no insurance that modeled ice crystal distributions describe the measurements correctly. As in Fig. 8, typical observed ice size distributions show the simultaneous presence of numerous small particles and large ones in a smaller amount. But considering only nucleation and deposition growth as microphysical processes in an air parcel frame leads to nearby monodispersive ice crystal size distributions (Fig. 8). None of these spectra, even the broader one with a varying deposition coefficient, would be able to fit the observations.

Applying some findings from the warm cloud microphysics, we could expect the stochastic collection processes of cloud elements to broaden the ice crystal size distribution. We already proved in the previous section that during the formation stage of the cirrus cloud the probability that a falling ice crystal captured a wet aerosol was really low. This low probability was not due to a lack of efficiency of particles to stick together but to the very low concentration of ice crystal and wet aerosol particles. The probability of them to collide was therefore negligible in the formation stage of cirrus cloud. If we now want to consider aggregation, that

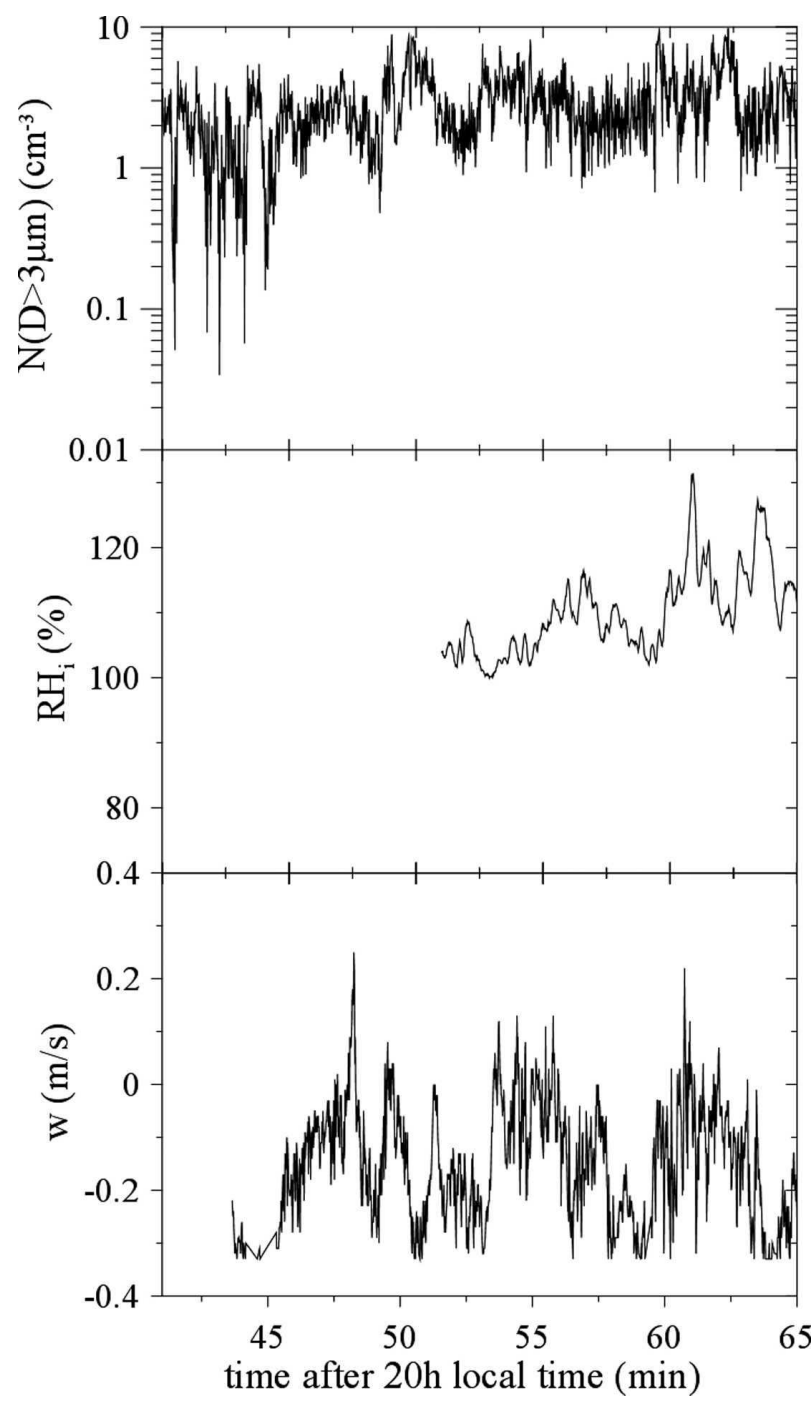

FIG. 9. Observations for the second flight of 31March for the flight leg in the formation region of the sampled cirrus cloud: (top) total number of particles measured by the combination of FSSP and 2DC probe particles with a diameter larger than $3 \mu \mathrm{m}$, (middle) relative humidity in respect to ice measured by the LMD hygrometer (Ovarlez et al. 2002), and (bottom) the vertical velocity of air.

means that the collection of an ice crystal by another ice crystal, to explain the broadening of ice crystal size distribution in formation region of cirrus clouds. Unfortunately, we face two major limitations. First, ice crystals are totally dry at cirrus temperatures and therefore cannot stick together. Furthermore, the absence of dendrite ice crystals in cirrus clouds also reduces the possibility of forming aggregates. Thus, the efficiency of ice crystal to aggregate if they collide will be very low. Second, the smallest concentration between aerosol particles and ice crystals is the crystal one with at least 
an order of magnitude in difference. If the concentrations of aerosol particles and ice crystal were too low to make a collision between them statistically relevant during the formation stage of the cirrus cloud, obviously the probability of the impact of ice crystals will be even more negligible in that stage. The lifetime of cirrus clouds could be really important. We do not claim that aggregation is a negligible microphysical process for cirrus clouds; we just conclude that it could not explain the observation of ice crystal size distribution only in the formation region.

To explain formation of rain in warm cloud microphysics, some studies (Young 1975; Zawadzki et al. 1994) showed how important the sedimentation of cloud elements with different fall speed is to explain, in addition to collision-coalescence processes, the broadening of raindrop size distribution. Since in our theoretical studies we are unable to explain the breadth of the ice crystal size distribution within the formation region of cirrus clouds, we need to use a vertical model to explain that failure. A proper case study has to be performed in a one-dimensional framework if we want to compare modeled and observed ice crystal size distribution.

\section{Modeling study of the formation region of the cirrus cloud sampled during the second flight on 31 March}

This flight took place at the beginning of the PA campaign. The sampled cirrus cloud was part of a system approaching from the west, with humid air in the entire troposphere. The flight procedure was identical to the other ones; it consisted of climbing to high altitudes above the main cloud layer and then performing several 10-15-min flight legs at different levels within the cloud. The cloud was composed of a thin layer aloft with some hundred meters of cloud-free air in between this layer and the main body of the cloud. The first flight level was performed at an altitude of about $10 \mathrm{~km}$ in the upper layer of the cloud. Other flight legs were performed afterward in the interior of the main part of the cloud.

As our model has been designed to study the formation of the cirrus cloud, we decided to simulate the thin top layer. Some of the measurements taken on that flight leg are shown in Fig. 9. The temperature was close to $-52^{\circ} \mathrm{C}$ at this altitude and the pressure was $260 \mathrm{mb}$.

To compare observations and simulations we used the two independent pieces of information provided by our model-that is, the knowledge of aerosol particle size distributions within the ice phase and interstitial in the air and the ice crystal size distributions.

\section{a. Study of the residual aerosol particle size distribution}

We performed an air parcel simulation to study the incorporation of aerosol particles through nucleation. We neglected the incorporation through impact as the observations are in the area of formation of cirrus clouds and collection of aerosol particles by ice crystal is mainly taking place at a more advanced age of cirrus clouds. The initial temperature was to set to be $-50^{\circ} \mathrm{C}$, and initial pressure to be $260 \mathrm{mb}$, in agreement with the observations. We exposed the air parcel to a constant vertical velocity of $10 \mathrm{~cm} \mathrm{~s}^{-1}$. Following our conclusions from section 4c; we expected only heterogeneous nucleation to be responsible for the observed residual aerosol particles. Therefore, we performed simulations with the three different parameterizations for heterogeneous nucleation. The initial aerosol particle size distribution was assumed to be an average of the measured aerosol particle spectra in air free of ice crystals. The aerosol particles were assumed to be a mixing of sulfuric acid and inertial silicates with a mass ratio of 1:1. The modeling results for the three parameterizations on the 31 March case are displayed in Fig. 10a. The behavior of the different heterogeneous nucleation rates confirms what was previously discussed in Fig. 6b. The parameterizations for heterogeneous nucleation DEM97 and DEM98 deviate from the observational results. This is due to the fact that these two approaches consider a size dependency for the ability of the particles to nucleate. The results would not have improved if we had used homogeneous nucleation parameterizations for which the size dependency is even more pronounced. However, it is surprising how well the MEY approach agrees with the observed crystal residual aerosol spectra. We should remember here that MEY do not provide any information on the size dependency of the nucleation ability of ice nuclei. It was our assumption that the efficiency is the same whatever is the size of the wet aerosol particle.

However, on this flight leg the ice crystal concentration was extremely small (only $234 \mathrm{~L}^{-1}$ ). Furthermore, the rate of incorporation of aerosol particles into the ice phase, which can be estimated roughly to be one per thousand (Fig. 10a), is small. Most of the cases show a rate of incorporation on the order of $1 \%$, as in the 27 September observations. We could conclude that this flight leg sampled the formation region of cirrus cloud and this formation is quite recent. This statement is reinforced by the strong ice supersaturation still visible 

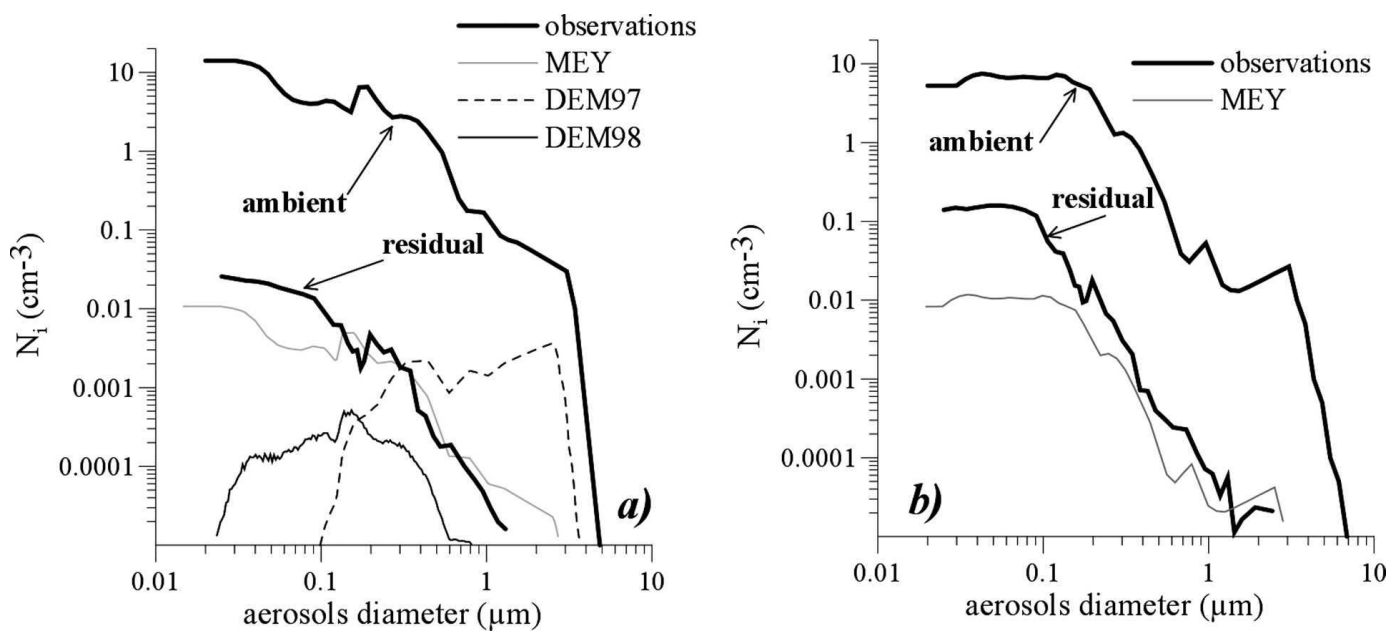

FIG. 10. (a) Measurements of the ambient and residual aerosol number distributions performed on 31 Mar on PA (thick lines). Modeling results, assuming the ambient measured spectrum as initial aerosols, for number distribution of the residual particles using the heterogeneous nucleation rates MEY, DEM97, and DEM98 are superimposed. (b) Same measurements for 27 September on PR compared with the modeling results of only the MEY scheme for heterogeneous nucleation.

in the observations in Fig. 9. The very high particle concentrations with a diameter greater than $3 \mu \mathrm{m}$ found in Fig. 9 are the consequence of the high concentrations of moist aerosol particles. Since humidity is still important these moist aerosol particles could easily have diameters larger than $3 \mu \mathrm{m}$. And finally the high concentration of particles, which is measured by the FSSP and the 2DC probes, does not indicate a high ice crystal number.

For 27 September, which is a case with an older formation region where the incorporation rate of aerosol particles in the ice phase has reached a typical value on the order of $1 \%$, the modeling result for MEY parameterization is given in Fig. 10b. In this more typical case, heterogeneous nucleation is again found to be not efficient enough to explain the high crystal concentrations. Indeed, we can see in Fig. 10b, that even the MEY parameterization, which was the best for the other flight, strongly underestimates the number of residual aerosol particles.

Therefore, we can conclude from this case study using an air parcel model that both homogeneous and heterogeneous nucleation fail to describe the incorporation of aerosol particles in ice crystals that was observed during most of the cases of the INCA campaign. The first mechanism strongly overestimates the ability of large aerosol particles to form ice crystals. The second underestimates the total number of formed ice crystals. In this context, the work of Ettner et al. (2004) might again help to explain the discrepancy. They observed that the chemical content of the supercooled droplet is instantaneously ejected at the freezing point to the ice crystal surface. The numerous small aerosol particles found in ice crystals could then be the remains of larger particles dissolved and ejected in several parts from droplets during the freezing process. This could be a possible explanation for the discrepancy between observed and modeled residual aerosol size distribution, however, this directly challenges the assumption that each ice crystal leaves only one particle after evaporating in the CVI.

\section{b. Study of the ice crystal size distribution}

We noted in section 5 that the impossibility of large particles to sediment and the absence of a water vapor supply in the cirrus clouds are the two main limitations of the air parcel framework to describe the cirrus clouds. That is why we developed a cylindrical model, including all the microphysical processes described earlier. We initialized our model with the profiles of temperature, pressure, and humidity given by the Falcon measurements. During the whole run the vertical velocity profile was prescribed and set constant in time even though the measurements showed important variability in the vertical velocity. Vertical velocity was assumed nonzero only between 7.5 and $12.5 \mathrm{~km}$, thus, it was prescribed as a second-degree polynomial function of the altitude with a zero value at 7.5 and $12.5 \mathrm{~km}$ and a maximum value of $15 \mathrm{~cm} \mathrm{~s}^{-1}$ at $10 \mathrm{~km}$. The three first panels in Fig. 11 show the profiles for initial temperature, relative humidity, and vertical velocity. 


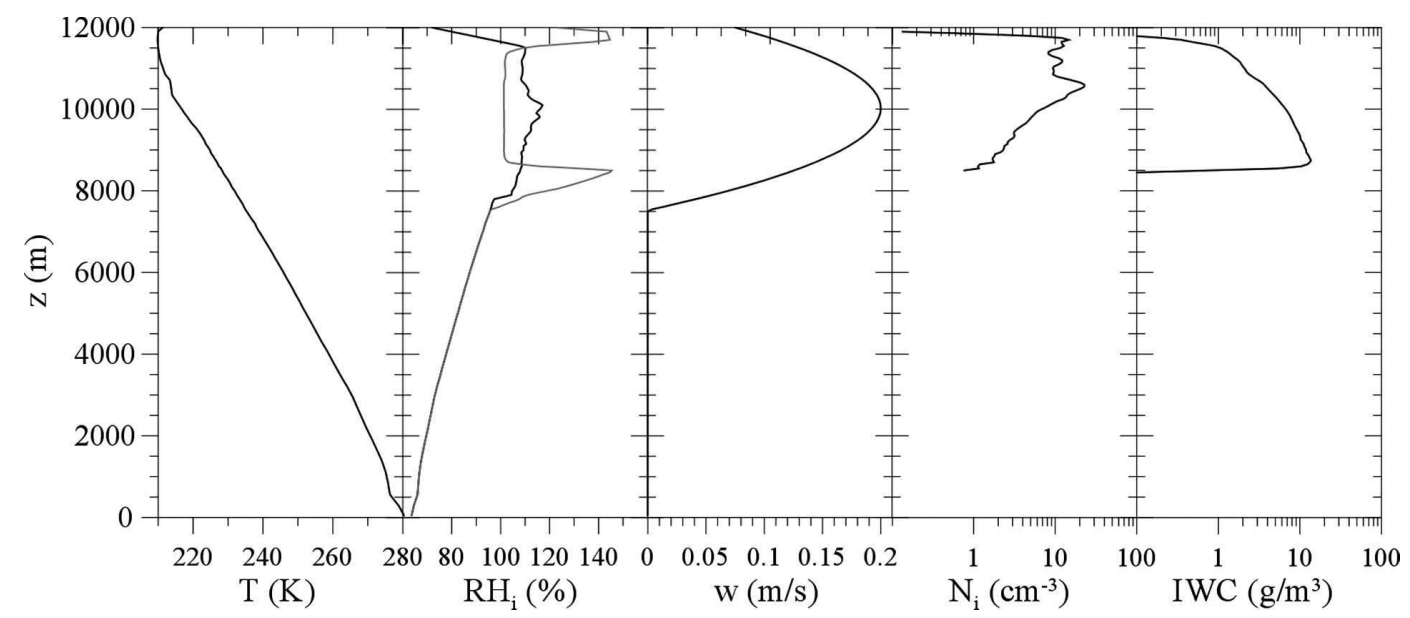

FIG. 11. Vertical profiles for the (left to right) initial temperature in $\mathrm{K}$, relative humidity in respect to ice at time 0 (black line) and modeled for $50 \mathrm{~min}$ (gray line) both in percentage, vertical velocity in $\mathrm{m} \mathrm{s}^{-1}$, ice crystal concentration in $\mathrm{cm}^{-3}$, and ice water content in $\mathrm{g} \mathrm{cm}^{-3}$. The two last profiles are given for the time of $50 \mathrm{~min}$.

We assumed the aerosol particles to be composed of pure sulfuric acid and uniformly distributed through the upper troposphere with a lognormal size distribution, matching the measurements of the Differential Mobility Particle Sizer (DMPS) and the Passive Cavity Aerosol Spectrometer Probe (PCASP) measurements at 10 $\mathrm{km}$ of altitude. Therefore we assumed a mean size of 20 $\mathrm{nm}$, a standard deviation of 2.3, and amplitude of 600 $\mathrm{cm}^{-3}$. We further considered the nucleation to be homogeneous and the solution effects through the TAB parameterization.

For the second flight leg we were in the formation region of the cloud. Moreover, the formation was recent as the remaining ice supersaturation was still high (Fig. 9) and the fraction of aerosol, which had served as nucleus, was quite small (Fig. 7). In that case, the use of our vertical model is appropriate since on a short period with low updraft speed, exchange between the two cylinders could be neglected and our model could be considered as only one dimensional. We also know that, for small time of integration, we can totally neglect collision-collection processes in the study of the ice crystal distribution.

The ice crystal concentrations and wet aerosol size distribution modeled after $50 \mathrm{~min}$ at an altitude of $10000 \mathrm{~m}$ are displayed in Fig. 12, with the total information on number particle size distribution given by the DMPS, PCASP, FSSP, and the 2DC probe. At 50 min, the profiles of ice crystal concentrations, relative humidity in respect to ice, and ice water content are given in Fig. 10. In Fig. 11, the agreement between observations and simulations is satisfactory. The modeled size distribution differs from a monodisperse function. This proves the importance of using use at least a one-dimensional model to study the ice crystal size distribution. However the model still fails to represent the larger mode near $80 \mu \mathrm{m}$. The mode around $8 \mu \mathrm{m}$ is overestimated. But the shape of the size distribution for sizes larger than $5 \mu \mathrm{m}$ is reproduced. We note that the model cannot explain the number of particles in the range of $1-5 \mu \mathrm{m}$. As mentioned earlier these particular observations differ from the main observed patterns as they are taken early in the formation stage. The other observations generally do not show a gap between 1

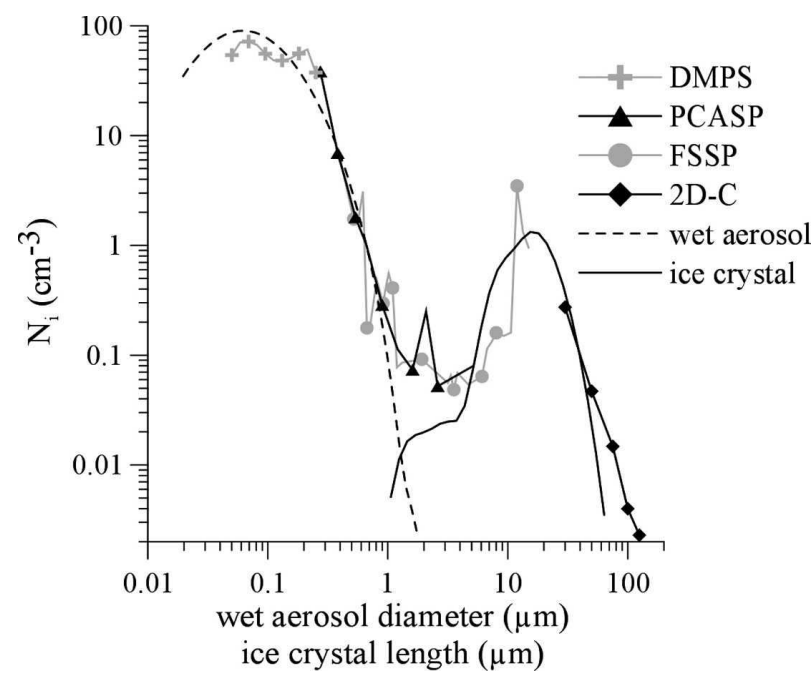

FIG. 12. Comparison of the particles number size distributions, which were on one hand simulated with the cylindrical model, and, on the other hand observed on the second Falcon plateau within cirrus clouds on 31 March. Measurements were performed with the DMPS, PCASP, FSSP, and 2DC probes. Simulations show together wet aerosol particles and ice crystals size distributions. 
and $5 \mu \mathrm{m}$. In our modeling results, large aerosol particles are not numerous enough to produce ice crystals by homogeneous nucleation and explain the number of observed particles in that size range. On the other hand, newly formed ice crystal of sizes less than $10 \mu \mathrm{m}$ have such a large depositional growth rate that they cannot remain in that size range for more than a few seconds. However before performing further modeling studies on ice crystal distributions, we also need to understand the nature of the particles observed by the PCASP and the FSSP within the size range from 1 to $10 \mu \mathrm{m}$.

\section{Conclusions}

In the present work we have developed a detailed microphysics model for the simulation of cirrus clouds, which describes the evolution of both solution droplet and ice crystal size distributions and individually follows their aerosol content. These evolutions are driven by water vapor diffusion growth, homogeneous and heterogeneous nucleation, and wet aerosol impact processes. These microphysical processes are treated within two different dynamical frameworks: the simple air parcel model with its Lagrangian dynamics and the vertical dynamical model with a possibility of particle sedimentation and a supply of water vapor in cirrus clouds. With these tools, we have been able to study how the interactions between the microphysical processes control ice crystal concentration, size distribution, and aerosol content.

We have shown, in particular, that for high ice crystal concentrations, homogeneous nucleation has to be considered alone in our model. However, to produce ice crystal concentrations as high as those observed during the INCA campaign for realistic vertical velocities, the rate of deposition growth has to be slowed down by decreasing the accommodation coefficient of water for at least small ice crystals, as proposed in Gierens et al. (2003). Compared to observations, if we consider nucleation to be homogeneous, the modeled nucleation ability is strongly overestimated for large aerosol particles and underestimated for small ones. These two limitations of homogeneous nucleation to reproduce the observations can be explained by the work of Ettner et al. (2004). Indeed our modeling does not take into account that, at the freezing point, the aerosol content of the droplet could be ejected in several pieces at the surface of the ice crystal. This can decrease the chance for water vapor molecules to reach the ice surface, and can break the large aerosol particles into several smaller fragments.

We showed that the uptake of moist aerosol particles by ice crystals through Brownian motion, phoretic effects, and inertial impact, is a negligible process in recently formed cirrus clouds. This weak efficiency is essentially due to the small ice crystal concentrations, since the encounter of an ice crystal with an aerosol particle is not likely. The use of a vertical dynamical model helped us to broaden the modeled ice crystal size distribution because the sedimentation of large particles with the supply of water vapor in cirrus layers are considered. This model is able to produce quite realistic size distributions. However, the model fails in particular to reproduce the observed particles between 1 and $10 \mu \mathrm{m}$. We can argue that in our simplified dynamic model, mixing of heterogeneous cirrus cloud regions cannot be described. Heterogeneity of the vertical velocity is of great importance in cirrus clouds as we note from the observations and, finally, it implies an important spatial heterogeneity for ice crystal distributions (Baker et al. 2000). Modeling studies with more realistic dynamics should be performed to investigate if horizontal mixing can explain these observations.

Finally, we are aware that further studies on different chemical compositions for aerosol particles and on different ice crystal shapes are needed to improve our insight into the interactions among all processes. The INCA observations' database contains more information to properly validate our cirrus cloud model and further studies should be performed to explain the observed differences in microphysical properties between the two campaigns (Punta Arenas, Chile, which is far from anthropogenic sources of aerosol particles in the upper troposphere, and Prestwick, Scotland, which is close to these sources). However, prior to these studies there is a need for laboratory studies to provide a better understanding about the competition between heterogeneous and homogeneous nucleation for an internally mixed aerosol, which leads to a solution droplet with an insoluble core. Furthermore, there is also a need to understand how the difference in the dynamical fields between the two campaigns influenced the observations in order to remove the variability of cirrus clouds resulting from dynamics, which might be as important as the microphysical part.

Acknowledgments. The authors are grateful to Henry Leighton and Charmaine Franklin for their help during the preparation of the manuscript. The calculations for this paper have been done on computer facilities of the "Institut du Développement et des Ressources en Informatique Scientifique" (IDRIS, CNRS) in Orsay (France) and the "Centre Informatique National de l'Enseignement Supérieur" (CINES) in Montpellier (France), under Project 940180. With gratitude the au- 
thors acknowledge the hours of computer time and the support provided.

\section{APPENDIX}

\section{List of Symbols}

$a_{g} \quad$ Radius of the germ immerged in the supercooled solution

$a_{w} \quad$ Water activity

$\alpha \quad$ Turbulent coefficient

$\beta \quad$ Parameter to fix the accuracy of the grid mesh

$c_{p} \quad$ Specific heat of air at constant pressure

$\Delta F_{\text {act }}$ Activation energy for displacement of the water molecule in the solution

$\Delta F_{g} \quad$ Free energy of germ formation

$\Delta T_{m} \quad$ Change of the freezing temperature of a droplet due to salt effect

$f_{\text {ice }}$ Three-dimensional number distribution function for iced particles

$f_{\text {wat }}$ Three-dimensional number distribution function for liquid drops

g Gravity constant

$H \quad$ Domain height

$h \quad$ Planck constant

$\eta_{w} \quad$ Solution viscosity

$J \quad$ Nucleation rate

$J_{\text {het }} \quad$ Heterogeneous nucleation rate

$J_{\text {hom }}$ Homogeneous nucleation rate

$K \quad$ Collection efficiency

$k \quad$ Boltzmann constant

$L \quad$ Latent heat associated with microphysical processes

$L_{m, 0} \quad$ Latent heat for pure water freezing

$\lambda$ Parameter accounting the nonideality of the solution in the freezing process

$M_{w} \quad$ Molecular weight of water

$m \quad$ Condensed particle mass

$m_{A P, N}$ Mass of the dry aerosol particle that has served as the nucleus

$m_{0 \text { crys }}$ Critical ice crystal mass for riming to be active

$m_{\text {0drop }}$ Critical droplet mass for riming to be active

$N_{\text {IN }} \quad$ Number concentration of ice nuclei

$N_{\text {AP }} \quad$ Number concentration of aerosol particles with a radius larger than $12 \mathrm{~nm}$

$N_{c} \quad$ Water molecule in contact with the ice-solution interface number

$N_{i} \quad$ Ice crystal concentration in the $i$ th model bin

$Q_{\text {diab }} \quad$ Diabatic heat sources

$q_{c} \quad$ Liquid water content

$q_{i} \quad$ Ice water content

$q_{v} \quad$ Vapor water content

$R \quad$ Universal gas constant
$\mathrm{RH}_{i} \quad$ Relative humidity over ice

$r \quad$ Humid aerosol radius

$r_{1} \quad$ Radius of the internal cylinder

$r_{2} \quad$ Radius of the external cylinder

$r_{\text {soot }}$ Radius of the soot particles immerged in a solution droplet

$\rho \quad$ Density of air

$\rho_{\text {ice }} \quad$ Density of ice

$\rho_{\text {sol }} \quad$ Density of the solution

$s_{v, i} \quad$ Supersaturation over ice

$\sigma \quad$ Ascent area density

$\sigma_{\text {ice/sol }}$ Surface tension of the ice-solution interface

$\sigma_{\text {sol/air }}$ Surface tension of the solution-air interface

$T \quad$ Air temperature

$T_{0} \quad$ Temperature of the triple point

$T_{\text {eff }} \quad$ Effective temperature of the solution

$\theta \quad$ Potential temperature

$\theta_{v} \quad$ Virtual potential temperature

$U_{\infty, \text { crys }}$ Terminal velocity of the ice crystal

$U_{\infty, \text { drop }}$ Surface tension of the ice-solution interface

$\tilde{u} \quad$ Radial velocity on the interface between the two cylinders

$V_{\text {sol }} \quad$ Volume of the solution surrounding the moist aerosol particle

$W \quad$ Vertical velocity

$w_{t s} \quad$ Weight sulphuric acid percentage

$x_{i} \quad$ Chemical composition for the $i$ th aerosol type

$Z \quad$ Altitude

\section{REFERENCES}

Asai, T., and A. Kasahara, 1967: A theoretical study of the compensating downward motions associated with cumulus clouds. J. Atmos. Sci., 24, 487-496.

Baker, B. A., R. P. Lawson, and C. G. Schmitt, 2000: Clumpy cirrus. Proc. 13th ICCP Conf., Reno, NV, ICCP, 637-641.

Bott, A., 2000: A flux method for the numerical solution of the stochastic collection equation: Extension to two-dimensional particle distributions. J. Atmos. Sci., 57, 284-294.

Boucher, O., 1999: Aircraft can increase cirrus cloudiness. Nature, 397, 30-31.

Brune, W. H., and Coauthors, 1999: $\mathrm{OH}$ and $\mathrm{HO}_{2}$ chemistry in the North Atlantic free troposphere. Geophys. Res. Lett., 26, 3077-3080.

Clegg, S. L., and P. Brimblecombe, 1995: Application of a multicomponent thermodynamic model to activities and thermal properties of $0-40 \mathrm{~mol} \mathrm{~kg}-1$ aqueous sulfuric acid from $<200$ to 328 K. J. Chem. Eng. Data, 40, 43-49.

DeMott, P., D. C. Rogers, and S. M. Kreidenweiss, 1997: The susceptibility of ice formation in upper tropospheric clouds to insoluble aerosol components. J. Geophys. Res., 102, 19575 19584.

—, Y. Chen, C. H. Twohy, D. Baumgardner, A. J. Heymsfield, and K. R. Chan, 1998: The role of heterogeneous freezing nucleation in upper tropospheric clouds: Inferences from SUCCESS. Geophys. Res. Lett., 25, 1387-1390. 
Dowling, D. R., and L. F. Radke, 1990: A summary of the physical properties of cirrus clouds. J. Appl. Meteor., 29, 970-978.

Ettner, M., S. K. Mitra, and S. Borrmann, 2004: Heterogeneous freezing of single sulphuric acid solution droplets: Laboratory experiments utilising an acoustic levitator. Atmos. Chem. Phys., 4, 1925-1932.

Gayet, J.-F., and Coauthors, 2002: Quantitative measurement of the microphysical and optical properties of cirrus clouds with four different in situ probes: Evidence of small ice crystals. Geophys. Res. Lett., 29, 2230-2233.

$\longrightarrow$, and - 2004: Cirrus cloud microphysical and optical properties at southern and northern midlatitudes during INCA experiment. J. Geophys. Res., 109, D20206, doi:10.1029/ 2004JD004803.

Gierens, K., R. Sausen, and U. Schumann, 1999: A diagnostic study of the global distribution of contrails. Part II: Future air traffic scenarios. Theor. Appl. Climatol., 63, 1-9.

— - M. Monier, and J.-F. Gayet, 2003: The deposition coefficient and its role for cirrus clouds. J. Geophys. Res., 108, 40694073.

Heymsfield, A. J., and J. Iaquinta, 2000: Cirrus crystal terminal velocities. J. Atmos. Sci., 57, 916-938.

—_, and G. M. McFarquhar, 2002: Mid-latitude and tropical cirrus: Microphysical properties. Cirrus, D. K. Lynch et al., Eds., Oxford University Press, 78-101.

Houghton, J. T., Y. Ding, D. J. Griggs, M. Noguer, P. J. van der Linden, X. Dai, K. Maskell, and C. A. Johnson, Eds., 2001: Climate Change 2001: The Scientific Basis. Cambridge University Press, $881 \mathrm{pp}$.

Jakob, C., 2002: Ice clouds in numerical weather prediction models: Progress, problems, and prospects. Cirrus, D. K. Lynch et al., Eds., Oxford University Press, 327-345.

Jensen, E. J., O. B. Toon, D. L. Westphal, S. Kinne, and A. J. Heymsfield, 1994: Microphysical modelling of cirrus. 1. Comparison with 1986 FIRE IFO measurements. J. Geophys. Res., 99, 10 421-10 442.

Kärcher, B., and J. Ström, 2003: The roles of dynamical variability and aerosols in cirrus cloud formation. Atmos. Chem. Phys., 3, 823-838.

Khvorostyanov, V. I., and J. A. Curry, 2000: A new theory of heterogeneous ice nucleation for application in cloud and climate models. Geophys. Res. Lett., 27, 4081-4084.

__ , and K. Sassen, 2002: Microphysical processes in cirrus and their impact on radiation: A mesoscale modelling perspective. Cirrus, D. K. Lynch et al., Eds., Oxford University Press, 397-432.

Koop, T., H. P. Ng, L. T. Molina, and M. J. Molina, 1998: A new optical technique to study aerosol phase transition: The nucleation of ice from $\mathrm{H}_{2} \mathrm{SO}_{4}$ aerosols. J. Phys. Chem., 102, 8924-8928.

- _ - B. Luo, A. Tsias, and T. Peter, 2000: Water activity as the determinant for homogeneous ice nucleation in aqueous solutions. Nature, 406, 611-615.

Lin, R.-F., D. Starr, P. J. DeMott, R. Cotton, K. Sassen, E. Jensen, B. Kärcher, and X. Liu, 2002: Cirrus parcel model comparison project. Phase 1: The critical components to simulate cirrus initiation explicitly. J. Atmos. Sci., 59, 2305-2319.

Martin, J. J., P. K. Wang, and H. R. Pruppacher, 1980: A theoretical determination with which aerosols particles are collected by simple ice crystal plates. J. Atmos. Sci., 37, 1628-1638.
Meyers, M. P., P. J. DeMott, and W. R. Cotton, 1992: New primary ice nucleation parametrizations in an explicit cloud model. J. Appl. Meteor., 31, 708-721.

Minikin, A., A. Petzold, J. Ström, R. Krejci, M. Seifert, P. van Velthoven, H. Schlager, and U. Schumann, 2003: Aircraft observations of the upper tropospheric fine particle aerosol in the Northern and Southern Hemispheres at midlatitudes. Geophys. Res. Lett., 30, 1503-1506.

Myrhe, C. E. L., C. J. Nielsen, and O. W. Sasstad, 1998: Density and surface tension of aqueous $\mathrm{H}_{2} \mathrm{SO}_{4}$ at low temperatures. $J$. Chem. Eng. Data, 43, 617-621.

Ovarlez, J., J.-F. Gayet, K. Gierens, J. Ström, H. Ovarlez, F. Auriol, R. Busen, and U. Schumann, 2002: Water vapour measurements inside cirrus clouds in Northern and Southern Hemispheres during INCA. Geophys. Res. Lett., 29, 18131816.

Pruppacher, H. R., and J. D. Klett, 1997: Microphysics of Clouds and Precipitation. $2 \mathrm{~d}$ ed. Kluwer Academic, $954 \mathrm{pp}$.

Ramanathan, V., and W. D. Collins, 1991: Thermodynamic regulation of ocean warming by cirrus clouds deduced from observations of the 1987 El Niño. Nature, 351, 27-32.

Reichardt, J., A. Ansmann, M. Serwazi, C. Weitkamp, and W. Michaelis, 1996: Unexpectedly low ozone concentration in midlatitude tropospheric ice clouds: A case study. Geophys. Res. Lett., 23, 1929-1932.

Sabinina, L., and L. Terpugov, 1935: Die Oberflachenspannung des systems Schwefelsaure-wasser. Z. Phys. Chem. Abt., A173, 237-241.

Sassen, K., and G. C. Dodd, 1989: Haze particle nucleation simulations in cirrus clouds, and applications for numerical and lidar studies. J. Atmos. Sci., 46, 3005-3014.

Seifert, M., J. Ström, R. Krejci, A. Minikin, A. Petzold, J.-F. Gayet, U. Schumann, and J. Ovarlez, 2003: In-situ observations of aerosol particles remaining from evaporated cirrus crystals: Comparing clean and polluted air masses. Atmos. Chem. Phys., 3, 1037-1049.

_, and Coauthors, 2004: Thermal, stability analysis of particles incorporated in cirrus crystals and of non-activated particles in between the cirrus crystals: Comparing clean and polluted air masses. Atmos. Chem. Phys., 4, 1343-1353.

Smolarkiewicz, P. K., 1983: A simple positive definite advection scheme with small implicit diffusion. Mon. Wea. Rev., 111, 479-486.

Starr, D., O'C., and M. Quante, 2002: Dynamic processes in cirrus clouds: Concepts and models. Cirrus, D. K. Lynch et al., Eds., Oxford University Press, 375-396.

Ström, J., 2001: Aerosol and cirrus measurements at midlatitudes on the Southern Hemisphere: An overview based on the first INCA experiment. Air Pollution Rep. 74, Rep. EUR 19, EN, European Commission Project EVK2-1999-00039, Brussels, Belgium, 428 pp.

Sundqvist, H., 2002: On cirrus modelling for general circulation and climate models. Cirrus, D. K. Lynch et al., Eds., Oxford University Press, 297-309.

Tabazadeh, A., S. T. Martin, and J. S. Lin, 2000: The effect of particle size and nitric acid uptake on the homogeneous freezing of aqueous sulfuric acid particles. Geophys. Res. Lett., 27, 1111-1114.

von der Emde, K., and P. Kahlig, 1989: Comparison of the observed 19th July 1981, Montana thunderstorm with results of 
a one-dimensional cloud model using Kessler parameterized microphysics. Ann. Geophys., 7, 405-414.

Wang, P., and J. Wusheng, 2000: Collision efficiencies of ice crystals at low intermediate Reynolds number colliding with supercooled cloud droplets: A numerical study. J. Atmos. Sci., 57, 1001-1009.

Wobrook, W., and Coauthors, 2001: The Cloud Ice Mountain Experiment (CIME): Experiment overview and modelling of the microphysical processes during the seeding by isentropic gas expansion. Atmos. Res., 58, 231-265.

Young, K. C., 1975: The evolution of drop size spectra due to condensation, coalescence, and break-up. J. Atmos. Sci., 32, 965-973.

Zawadzki, I., E. Monteiro, and F. Fabry, 1994: The development of drop size distributions in light rain. J. Atmos. Sci., 51, 1100-1113. 